University of Wollongong

Research Online

Faculty of Business - Papers (Archive)

Faculty of Business and Law

2017

Biting Back at Malaria: Assessing Health-service Providers' Compliance with Treatment Guidelines

Alfredo R. Paloyo

University of Wollongong, apaloyo@uow.edu.au

Arndt R. Reichert

Rheinisch-Westfalisches Institut Fur Wirtschaftsforschung

Follow this and additional works at: https://ro.uow.edu.au/buspapers

Part of the Business Commons

Research Online is the open access institutional repository for the University of Wollongong. For further information contact the UOW Library: research-pubs@uow.edu.au 


\title{
Biting Back at Malaria: Assessing Health-service Providers' Compliance with Treatment Guidelines
}

\author{
Abstract \\ Non-compliance with established medical treatment guidelines can have dire consequences for public \\ health and economic well-being. Based on the Demographic and Health Surveys, we examine malaria \\ treatment practices of various health-care providers in sub-Saharan Africa, where more than $90 \%$ of \\ malaria-induced deaths occur. We estimate each provider's likelihood (i) to comply with guidelines to \\ administer (effective) antimalarial drugs and (ii) to relieve children of fever-a symptom of malaria-after \\ having had a fever episode within the previous two weeks. Our results indicate that, relative to self \\ medication, seeking treatment at most providers is positively associated with taking an antimalarial drug \\ and negatively associated with using only ineffective chloroquine. Non-traditional healers are also \\ associated with fever relief. \\ Disciplines \\ Business

\section{Publication Details} \\ Paloyo, A. R. \& Reichert, A. R. (2017). Biting Back at Malaria: Assessing Health-service Providers' \\ Compliance with Treatment Guidelines. Review of Development Economics, 21 (3), 591-626.
}




\title{
Biting back at malaria: Assessing health-service providers' compliance with treatment guidelines*
}

\author{
Alfredo R. Paloyo and Arndt R. Reichert
}

\begin{abstract}
Non-compliance with established medical treatment guidelines can have dire consequences for public health and economic well-being. Based on the Demographic and Health Surveys, we examine malaria-treatment practices of various health-care providers in sub-Saharan Africa, where more than 90 percent of malaria-induced deaths occur. We estimate each provider's likelihood (a) to comply with guidelines to administer (effective) antimalarial drugs and (b) to relieve children of fever-a symptom of malaria-after having had a fever episode within the last two weeks. Our results indicate that, relative to self-medication, seeking treatment at most providers is positively associated with taking an antimalarial drug and negatively associated with using only ineffective chloroquine. Non-traditional healers are also associated with fever relief.
\end{abstract}

JEL Classification: I11, I14, 015, 057

Keywords: Demographic and Health Survey; malaria; presumptive treatment; subSaharan Africa

There are no conflicts of interest to declare.

${ }^{*}$ This article was written when both authors were primarily employed at the Rheinisch-Westfälisches Institut für Wirtschaftsforschung (RWI). We acknowledge the support of Christoph Helbach, Jörg Peters, Emmanuel San Andres, Maximiliane Sievert, Christoph Strupat, and participants of the German Health Economics Association meeting in 2013, the research seminars of the RWI and the School of Accounting, Economics, and Finance of UOW. 


\section{INTRODUCTION}

Evidence-based treatment guidelines for diseases are regularly provided at the national and international levels. At the national level, these guidelines are issued either by the Ministry or Department of Health or by the professional regulatory associations; multilateral bodies, such as the World Health Organization (WHO), also prescribe how diseases should be treated. These guidelines are designed to improve health care and outcomes and to lower the cost of service provision. Deviations from the prescribed treatment protocol could result in ineffective and inefficient treatment. For communicable diseases, insufficient compliance will likely contribute to the spread of drug-resistant mutations of an infectious microorganism. As such, compliance with mandated guidelines is one indicator for the quality of health-service provision (Hesdorffer et al., 2002; Karbach et al., 2011; Sekhon et al., 2013).

The present paper is concerned with the compliance of health-service providers with international and national treatment guidelines for uncomplicated malaria. ${ }^{1}$ While these guidelines have rightfully changed over time in response to new evidence, declining prevalence, and the increasing availability of rapid diagnostic tests (RDT), our study time frame is primarily the period during which presumptive treatment of childhood malaria was the prescribed protocol. Under such a regime, antimalarial drugs should be administered to children if they present with fever even without a clinical confirmation of malaria. The rationale behind such a regime in regions like sub-Saharan Africa is that malaria is endemic to the area, with transmission rates that are quite high. This implies that the most likely underlying cause of a fever episode in children is malaria (Cohen et al., 2015), which should be treated immediately to improve the likelihood of being cured. Current WHO guidelines (2010) recommend "test and treat" (i.e., confirm the presence of the malaria parasite in a febrile child), but this is only possible where RDT kits are available or where access to trained personnel can lead to a confirmation.

\footnotetext{
1 "A patient who presents with symptoms of malaria and a positive parasitological test...but with no features of severe malaria is defined as having uncomplicated malaria" (WHO, 2015, p. 32).
} 
In our study, we analyze the differences in febrile-children-treatment practices between selftreatment, traditional healers, private health-care providers, and the public sector in western subSaharan Africa. We specifically assess the treatment provided to children below five years old who had fever within the last two weeks by comparing the use patterns of antimalarial drugs and feverabatement rates. We interpret the likelihood of taking effective antimalarial drugs for febrile children as a indicator of overall quality because such adherence to treatment guidelines is-in the words of an anonymous reviewer- "indicative of an understanding, appreciation, and commitment to evidencebased medicine".

We contribute to the emergent development-economics debate on the quality of medical care in two ways. First, we present a novel way to assess the overall quality of medical care. While actual compliance with prescribed treatment guidelines as an indicator of overall health-care quality is not novel per se (e.g., Nshakira et al., 2002; WHO, 2003; Tavrow, Shabahag, and Makama, 2003), we propose to leverage the use of standardized household survey data such as the Demographic and Health Surveys (DHS), which is available in over 90 countries, as opposed to conducting costly provider interviews (e.g., Ebtong et al., 2012). ${ }^{2}$ For policymakers and practitioners in the field of development, our analysis can be seen as another useful way to assess the quality of health-services providers, one that is much cheaper than administering, for example, clinical vignettes. Second, we present further empirical evidence on the overall quality of health care in the developing world. Generally, more evidence is needed to uncover areas where health systems fail so that appropriate measures to strengthen the health system may be put in place (Berman and Bitran, 2011).

The rest of the paper is structured as follows. Section 2 provides a discussion of related research on treatment practices and describes how we advance the literature. Section 3 contextualizes the issue of malaria in sub-Saharan Africa as well as the treatment regimes that are currently in place. Section 4 briefly describes the data and the study population while Section 5 presents the estimation approach

\footnotetext{
2 Alternative measures of quality thus far have been predominantly assessed based on input factors, such as the physical infrastructure and the stock of medical supplies (e.g., Collier et al., 2003). More recently, clinical vignettes in combination with item response are used to assess treatment quality (Das and Hammer, 2005; 2007).
} 
and the results. Section 6 offers an a discussion of the the heterogeneity across countries and over time before finally concluding in Section 7.

\section{RELATED LITERATURE}

Our understanding of the treatment practices of health-care providers and treatment-seeking behavior of malaria-infected individuals is asymmetric. While our knowledge of the latter is informed by a large body of evidence in the medical and social sciences (see McCombie (1996), for example), how providers behave-especially their treatment practices-is insufficiently explored in the existing literature. Indeed, as Williams and Jones (2004, p. 511) point out, "little emphasis has been given to examining how providers prescribe antimalarials." Quality differences between health-care providers presumably exist, but the magnitudes of these differences—-to our knowledge-have not always been explored with methodological rigor.

A few studies on antimalarial drug provision of different health-care providers (e.g., Onwujekwe et al., 2009; Smith et al., 2010; Ebong et al., 2012) exist, but the evidence is restricted to single countries and-due to a regional focus within these countries-are usually not representative of the population. Thus, the external validity that arise out of these estimates is limited. We use the nationallyrepresentative Demographic and Health Surveys (DHS) for eight West African countries (Benin, Burkina Faso, Ghana, Guinea, Liberia, Mali, Niger, and Nigeria) which allow us to assess heterogeneity in febrilechildren-treatment practices across countries.

Some studies examine the compliance only of health professionals without comparing them to traditional healers (Ughasoro et al., 2013). This is a significant gap since evidence suggests that traditional healers may, under certain conditions, be able to provide better health services to their patients. Leonard (2003) shows that traditional healers could be better because of the nature of the contract between the service provider and the patient. These contracts are typically outcomecontingent - that is, a traditional healer will not get paid unless the desired outcome (being cured) is achieved. Both the patient and the healer, therefore, will have an incentive to increase their effort to be cured. The contract between the patient and a health professional, however, is not contingent on being 
cured. In this paper, we explicitly compare the outcomes achieved by the formal sector relative to those achieved both by self-medication and going to traditional healers.

Understanding these quality differences is important because "in sub-Saharan Africa, the pragmatic choice for prompt and effective treatment (especially for uncomplicated malaria) currently lies outside the formal health sector" (Williams and Jones, 2004, p. 514). Based on our dataset, the share of children undergoing self-medication is about a fifth of the population of febrile children. In Burkina Faso, for example, it is over 50 percent. Over 17 percent of febrile children in Benin go to a traditional healer. While these health-care providers may be prompt at delivering some type of medication, the effectiveness of these drugs is rightly questionable. The extent to which these providers comply with national and international treatment guidelines is an important measure to assess their quality.

To this end, we are the first who aim to extensively control for confounding factors, such as the educational background of the guardians. The guardian's education, for example, is likely to be related to both health-care provider choice and knowledge of effective malaria treatments. Thus, we mitigate spurious correlations better than previous studies, which abstain from employing multivariate regressions and are based merely on regional samples within a country. We also assess whether there exists a socioeconomic gradient in the quality of malaria treatment across different providers. We further examine differences in treatment practices across countries and, hence, institutional settings. Similarly, we compare Ghana and Nigeria over two years to give an indication of how different policy implementations affect treatment practices. Although the countries we examine all belong to western sub-Saharan Africa, national health institutions could potentially be quite different between countries, and this should be taken into account in the analysis.

\section{BACKGROUND}

Malaria kills about 660,000 people each year. The majority of deaths (86 percent) occur in children below five years of age. Approximately 1,500 children die due to malaria every day. Most of them are located in sub-Saharan Africa, where the highest malaria-parasite prevalence rates are reported for children among poorer populations and in rural areas (WHO, 2012). These figures are generally 
preceived as unacceptable since malaria is considered as an entirely preventable and treatable disease. As a consequence, bilateral donors, the World Bank, and the Global Fund to Fight AIDS, Tuberculosis and Malaria have substantially increased malaria-control funding and provided technical assistance through the World Health Organization (WHO) and the Roll Back Malaria Partnership for years. In fact, international disbursements for malaria control rose from US\$100 million in 2000 to US\$1.71 billion in 2010, a 17-fold increase.

The principal vector for malaria is the female Anopheles mosquito which carries the malaria parasite, a Plasmodium protozoan. The five species that have been documented to cause malaria in humans are Plasmodium falciparum, P. vivax, P. malariae, P. ovale, and, rarely, P. knowlesi (WHO, 2014a). The P. falciparum variant accounts for the majority of deaths due to malaria followed by P. vivax. The geographic region under study-western sub-Saharan Africa-is susceptible primarily to P. falciparum, since $P$. vivax does not commonly infect people who belong to the Duffy-negative blood group to which most people from West Africa belong (Ménard et al., 2010). There is grave concern worldwide with the spread of multi-drug-resistant $P$. falciparum and the insecticide-resistant mosquito vector since $P$. falciparum is also the most virulent strain.

Our study region is a hotbed for P. falciparum malaria. Based on information from the World Malaria Report 2014 (WHO, 2014b), about 128 million people were infected by P. falciparum in 2013. West Africa had the highest rates of infection for children aged 2-10 years. In 15 sub-Saharan countries, over a fifth of the children's population is infected. Fortunately, the trend is declining: "Eight subSaharan countries are estimated to have achieved declines of [over 75 percent], and 14 countries achieved declines of [over 50 percent] between 2000 and 2013" (WHO, 2014b, p. 35).

The treatment for uncomplicated malaria traditionally consisted of a regimen of chloroquine (CQ). However, resistance to CQ has been known since the 1950s. Almost the whole of tropical and subtropical Africa shows an elevated level of CQ-resistant P. falciparum malaria (Figure 1). For a time, sulphadoxine-pyrimethamine (SP) replaced CQ as the first-line treatment regimen for uncomplicated malaria, but it did not remain effective. 
More recently, combination therapies are recommended to prevent the spread of multi-drugresistant parasites. Over the last few years, especially beginning in 2004, most African countries have transitioned to artemisinin-based combination therapies (ACTs), with South Africa beginning in 2001. Although Malawi was the first in this region to transition out of CQ in 1993 (CQ was replaced with SP as the first-line treatment), it was the last to adopt ACTs together with Botswana in 2007 (Flegg et al., 2013). The sub-Saharan and West African countries included in this study have all adopted artemisininbased therapies in recent years.

The WHO (2006b) notes that artemisinin derivatives marketed in some countries are monotherapies. This practice, "if unabated, will promote development and spread of resistance and compromise the effectiveness of ACTs." It is therefore important that health practitioners comply with the national guidelines that recommend combination therapies as the first-line treatment. First, it prevents the use of ineffective medicine, such as either CQ or SP; second, it prevents the emergence and spread of multi-drug-resistant parasites, against which the international community has not yet developed effective alternatives.

The current evidence shows that national and global efforts at encouraging ACTs are bearing fruit: the prevalence rate of $P$. falciparum in children aged 2-10 in sub-Saharan Africa has declined "from $37 \%$ in the years 1985-1999 to 17\% in 2000-2007" (D'Acremont et al., 2009). This fact, coupled with the increasing supply and decreasing cost of RDTs, have generated a debate about the usefulness of the presumptive treatment regime in P. falciparum-endemic countries. With the declining prevalence of the parasite, the risk of mistreatment or overtreatment with ACTs increases, which could have negative consequences in terms of its adoption. As Adhvaryu (2014) demonstrates using data from Tanzania, if ACTs are overprescribed, its widespread adoption may be impaired by the fact that some of its recipients may not even have malaria. In that case, ACTs may not do anything to cure the underlying true cause of the disease, prolonging the fever episode (or some other worse outcome). Patients may then conclude that ACTs are ineffective against malaria, which could lead to an unwanted decline in ACT use. 
Although the medical community is not unanimous, the WHO has already abandoned presumptive treatment in favor of a "test and treat" (and track) strategy: "In all settings, suspected malaria should be confirmed with a parasitological test." (WHO, 2015, p. 29) As noted elsewhere, this is a remarkable departure from previous guidelines (Graz et al., 2011), which allowed for presumptive treatment especially in malaria-endemic areas with high transmission rates. The test-and-treat approach is meant to ensure that malaria drugs are only used in actual malaria cases. This change also reflects the fact that RDTs are now much more widely available. ${ }^{3}$ Fortunately, recent data show that diagnostic tests now exceed the number of ACTs distributed in the public sector (WHO, 2014b). Since not all presentations of fever are necessarily malaria, we expect that testing should always exceed treatment, so this is positive news.

The WHO recommendation of treating uncomplicated malaria with ACT as a first-line treatment for P. falciparum malaria has been widely adopted in the African region. Of the 44 countries where P. falciparum malaria is endemic, 43 have already adopted ACT (WHO, 2014b). All West African countries included in this study have adopted artemisinin-based combination therapies in recent years.

Regarding adoption of the test-and-treat approach, "the WHO African Region has seen the largest increase in the proportion of suspected cases tested, from 47\% in 2010-when WHO's recommendation to test all suspected malaria cases was introduced-to 62\% in 2013." (WHO, 2014b, p. 20)

According to the latest WHO country profiles (WHO, 2014b), all countries in our paper have also at least nominally adopted the testing regime, with the earliest one being Liberia in 2005 and the latest one being Guinea in 2012. Previously, presumptive treatment was in place. Unfortunately, "nearly $40 \%$ of people with suspected malaria at public health facilities in Africa are not tested", ${ }^{4}$ implying that there remains a significant divide between the international guidelines and national implementation.

\footnotetext{
3 “[RDTs] are now widely available and more than 319 million were purchased in 2013 compared to 46 million in 2008," according to a WHO news release available from http://goo.gl/DfdpJn.

${ }^{4}$ WHO news release available from http://goo.gl/DfdpJn.
} 
While the proportion of children in sub-Saharan Africa receiving ACT for P. falciparum malaria has been increasing, it remains below 20 percent at least until 2013; in public health facilities, the proportion ranged from 9 to 26 percent (WHO, 2014b). The WHO attributes this relatively low percentage to the fact that febrile children are not brought in for care. According to the same report, ACTs have at least been replacing other antimalarial drugs across the board (both public and private sectors), and that the increased use of RDTs could ensure that ACTs are delivered only to those who actually have malaria.

Prompt and effective malaria treatment is a key component of the global strategy to reduce the burden of the disease (RBM, 2005). One reason for the low usage of antimalarial medication in the treatment of young children in sub-Saharan Arfica could simply be the misinterpretation of the main symptom of malaria, which is fever, a disease that has a variety of etiologies. Hence, without microscopy or other diagnostic tests, febrile children's parents and guardians can fail to appreciate the gravity of the underlying cause and dismiss fever as the result of some other-perhaps less fatal-disease, such as the common cold. Except perhaps among the most uneducated subpopulation in the most isoalted regions, it would be difficult, however, to find mothers who are unfamiliar with malaria in West Africa.

Even if children's guardians know that a fever episode is likely caused by malaria, they used to abstain from administering antimalarial drugs (McCombie, 1996). More recent evidence (Adhvaryu, 2014) note that overtreatment is more common. The recommendation by both national and international guidelines prevailing during the period of study, however, state that children presenting with fever should be presumed to have malaria, and that an antimalarial treatment cycle should immediately be started (WHO, 2012). Moreover, of those who decide to give their children anitmalarial drugs, many rely on ineffective medicine such as CQ. ${ }^{5}$

Although some guardians bring their febrile children to health facilities instead of selfdiagnosing and self-medicating, this is still not a guarantee that appropriate treatment will be provided, as shown by several regional case studies (e.g., Onwujekwe et al., 2009). These studies suggest that there

\footnotetext{
${ }^{5}$ The use of CQ is strongly discouraged due to widespread $P$. falciparum resistance to CQ in that part of the world.
} 
exists a substantial degree of heterogeneity in the quality of malaria treatment across different types of health-care providers (e.g., public versus private health facilities). Consequently, there should be an emphasis on the importance of the guardian's decision on whether and where to seek advice for the treatment of febrile young children. This sheds light on understanding the observed low levels of (effective) antimalarial drug use (e.g., Smith et al., 2010).

Despite this compelling set of facts - the combination of high mortality and morbidity, drugresistant parasites, wildly varying quality of care-malaria, an entirely preventable and curable (with relatively cheap drugs) disease, remains poorly managed even by trained health professionals in P. falciparum-endemic countries in Africa (Brugha and Zwi, 1998; Ofori-Adjei and Arhinful, 1996; Williams and Jones, 2004). Clinical guidelines are under constant review (which typically can be considered a good thing, except that keeping guidelines in flux may make it more difficult for health practitioners to comply with them), the global fund to make drugs more economically accessibleAffordable Medicines Facility-malaria (AMFm) - has been rolled back (Cohen et al., 2015), and underwhelming compliance with guidelines have negative consequences in the short run (e.g., the burden of the disease on those who are infected) but also in the long run (when multi-drug-resistant parasites spread even further).

\section{DATA AND STUDY POPULATION}

The data for the analysis come from the Demographic and Health Surveys (DHS) conducted for eight selected West sub-Saharan African countries, namely Benin, Burkina Faso, Ghana, Guinea, Liberia, Mali, Niger, and Nigeria. Further details about the DHS are available from the Measure DHS website at http://measuredhs.com. The DHS are nationally representative, consisting of three core questionnaires: the women's, the men's, and the household questionnaire. Sociodemographic characteristics are collected for purposes of, among others, assisting policymakers in these countries to implement instruments to improve public health.

We use one wave for Benin (2006), Burkina Faso (2003), Guinea (2005), Liberia (2006-2007), Mali (2006), and Niger (2006). We use two waves for Ghana (2003 and 2008) and Nigeria (2003 and 
2008). Since the focus of the paper is on the compliance of the provider with the treatment guidelines for malaria, we restrict the sample only to those children who exhibited fever within the last two weeks (according to the mother). The final pooled estimation sample consists of child-level data for 19,267 children, of which 18,069 lie within the so-called "common support" (for details, see Sec. 4).

The outcome variables are (1) the probability of receiving antimalarial drugs, (2) the probability of receiving "good" antimalarial drugs, (3) the probability of receiving only CQ, and (4) the probability of having fever at the time of the interview. Good antimalarial drugs, which are essentially combination therapies of different antimalarial drugs (typically based on artemisinin), are the recommended first-line treatment for uncomplicated $P$. falciparum malaria according to national guidelines at the time of the interviews (see Table A3 in the Appendix). ACTs have been shown to be effective treatments for malaria in the presence of CQ resistance, which is the case in the eight countries examined in this paper (Figure 1). We exclude the year 2003 from the analysis of good antimalarial drug administration because national guidelines in respective countries (Burkina Faso, Ghana, and Nigeria) recommended CQ as first-line treatment. Otherwise, the definition of what constitutes "good antimalarial" always means that compliance with prevailing guidelines is good even if the guidelines require the use of $\mathrm{CQ}$.

Following the definition of Filmer (2005), our health-service-provider indicators are for (1) going to a public hospital, (2) going to a public health facility which is not a hospital, (3) going to a private hospital, (4) going to a private health facility which is not a hospital, (5) going to a pharmacy or a shop, (6) going to a traditional healer, or (7) "self-medicating" (i.e., no advice is sought by the guardian). These constitute all the potential providers available to the guardian, including selfmedication or no treatment. We remove observations where the child was in contact with more than one treatment provider (about 2 percent of the sample). This is not likely to be problematic given the small number, although one could imagine that those children who have had contact with more than one provider did so because the first one was unsuccessful, implying either that these are worse cases or the children did not receive appropriate medication from the initial provider. 


\section{ESTIMATION AND RESULTS}

\subsection{ESTIMATION APPROACH}

We estimate linear probability models (LPM) for four different binary outcome variables using a set of five provider indicators (with self-treatment as the reference category) and further control variables as regressors. The LPM, despite allowing for predicted probabilities outside the unit interval, remains the best linear predictor and, in practice, does well as an estimator for marginal effects (Angrist and Pischke, 2009): "If the main purpose of estimating a binary response model is to approximate the partial effects of the explanatory variables, averaged across the distribution of [the explanatory variables], then the LPM often does a very good job." (Wooldridge, 2010, p. 563) Although the LPM also introduces heteroskedasticity by construction, the statistical inference presented below is robust to heteroskedasticity. Nonetheless, our estimates of marginal effects obtained via the LPM do not vary substantially from those reported by nonlinear estimators (viz. probit and logit).

The estimated coefficients of the provider indicator variables yield the difference (in the probability of a positive outcome in the dependent variable) between the respective health-care providers and self-treatment or self-medication conditional on the covariates. Quality differences between two health-care providers are reflected in differences between the respective coefficients of the various providers. Wald tests are used to assess whether both coefficients significantly differ from each other.

The basic LPM we use in the analysis below takes the following form:

$$
y_{i j t}=\beta_{0}+\boldsymbol{\beta}_{\mathbf{1}}^{\prime} \mathbf{P}_{i j t}+\boldsymbol{\beta}_{\mathbf{2}}^{\prime} \mathbf{X}_{i j t}+\epsilon_{i j t},
$$

where the left-hand side represents a binary outcome variable, $y_{i j t}$ for child $i$ in country $j$ at time $t$. The vector of provider choices is contained in $\mathbf{P}_{i j t}$ and other control variables are in the vector $\mathbf{X}_{i j t}$ (which includes country-specific region and time (year-month combination) fixed effects, which are intended to capture secular differences between countries and over time that are not already captured by the 
other independent variables). The variables contained in the vector $\mathbf{X}_{i j t}$ increase incrementally as described below to show the robustness of the estimated coefficients to the inclusion of socioeconomic well-being and environmental characteristics. The standard errors are robust to heteroskedasticity.

The four outcome variables are usage indicators for any, effective, and ineffective (CQ) antimalarial drugs, as well as an indicator for the child having a fever at the time of interview. The reported drug use is construed to measure the drug pressure in the community (Flegg et al., 2013). We condition the estimations for the effective and ineffective antimalarial drug variables on children who have taken any antimalarial drug. This completes our construction of quality (based on drug use) because antimalarial-drug in-take alone does not necessarily indicate better quality. While the first three indicators measure the appropriateness of the treatment, the fever regressions are informative about the ultimate effectiveness of the provider.

Besides the risk of being entirely ineffective, antimalarial treatment may be inappropriate if the child's illness is, in reality, not due to malaria. In order to prevent parasite resistance to antimalarial drugs, their use should be restricted to presumed and actual malaria cases. ${ }^{6}$ This holds strongly for providers that are able to use rapid antigen tests, microscopy, serology, or some other diagnostic procedure. In cases where a provider advises antimalarial drug use (irrespective of whether the diagnostic test returned a positive result or the diagnosis was presumptive), the choice of treatment must nevertheless be an effective antimalarial drug (i.e., combination therapy). There is no reason to exclusively administer CQ due to its well-known and widespread ineffectiveness against the dominant malaria parasite in this region.

The central problem for our econometric analysis is to accurately determine the expected counterfactual outcome for febrile children in treatment at a certain health-care provider. The LPM allows

\footnotetext{
${ }^{6}$ However, if much of the fever cases are not due to P. falciparum malaria, the presumptive treatment regime will lead to over-treatment, which has been shown to be harmful to both the recipient of the drug and to society in general, as it could lead to a slower adoption of the appropriate therapeutic choice (Adhvaryu, 2014; Cohen et al., 2015). Although these phenomena are interesting and important, the current manuscript's objective is to measure the compliance rate of different health providers with the national guidelines. Whether the guidelines themselves have much wisdom behind them is not our focus, though it is certainly important to consider in the realm of public health.
} 
us to base the estimation of the counterfactual state on a large set of individual characteristics, environmental factors, region, and time of the interview. Nevertheless, there are a number of things that remain unobserved, such as the severity of illness, the cost of treatment (including the distance to the provider, which has been shown to significantly impact the likelihood of seeking treatment (Williams and Jones, 2004, and the references cited in Table 6 of their paper), and other determinants of health-services demand. At least with the severity of illness, we are able to use variables such as the use of bed nets and access to safe water as proxies for the likelihood of the fever being due to malaria (e.g., bed nets reduce mosquito bites). We acknowledge, however, that these measures are imperfect, and they are in any case insufficient to address the other omitted variables that may cause estimation issues.

By employing many covariates, we run the risk of projecting into regions where there are no data points. To prevent this, we restrict our analysis to the "common support", i.e., we ensure that, for each treated febrile child, there is a comparable child in the self-medication category, at least in terms of observable characteristics. To determine the common support, we first calculate the minimum and maximum predicted probabilities of being in the self-medication category for all observations. We use a multinomial logit model to estimate the likelihoods to fall into each of the categories (self-medication, traditional healer, pharmacy/shop, private hospital, other private, public hospital, or other public) based on control variables (but without the region and year indicators to introduce some coarseness and consequently increase the area of overlap). The parameter estimates are then used to calculate the predicted probability of being in the self-medication category for each observation. Figure 2 illustrates the distribution of the predicted probabilities of being in the self-medication category by each healthcare provider.

We then trim the sample by excluding observations that have predicted probabilities that are either higher than the maximum predicted probability of any of the categories or lower than the minimum predicted probability of any of the categories. Restricting the estimation sample to the common support resulted in the exclusion of 1,198 observations (about 6 percent of the original sample). Note that trimming the sample implies that the resulting estimates are consistent only for observations that lie within the common support (Lechner, 2008), which ensures the comparability of observations with 
different provider choices. Nevertheless, none of our empirical claims are sensitive to the inclusion of observations outside the common support.

\subsection{DESCRIPTIVE STATISTICS}

The means of the outcome and provider-choice variables by country are presented in Table 1. For four out of the eight countries in the sample (Burkina Faso, Benin, Ghana, and Liberia), more than 50 percent of febrile children are treated with antimalarial drugs. While Benin ranks high in terms of antimalarial drug provision, it is among the worst (together with Nigeria) performers with respect to the provision of good antimalarial drugs, conditional on providing any antimalarial drug at all. In the sample, only 35.9 percent of Mali's children with a fever episode within the last two weeks received any antimalarial drug. Worryingly, even though the region is widely acknowledged to have CQ-resistant parasites, nontrivial shares of febrile children received the ineffective treatment (e.g., almost half the febrile children in Burkina Faso are treated only with CQ although of course CQ was the prescribed first-line treatment in Burkina Faso at that time, together with Ghana and Nigeria in 2003 even in the presence of CQ-resistant parasites). Fever abatement is highest in Niger, with about 80 percent of the children presenting with fever over the last two weeks no longer having fever at the time of the interview; Nigeria is the worst performer, with a "cure rate" of only 65 percent

In terms of provider choice, apart from Benin and Mali, going to a traditional healer seems to be a marginal phenomenon. Typically, a large share of the febrile children in this region goes to some public health facility which is not a hospital for treatment, with the only exception being Ghana, where most are taken to either a public hospital or a pharmaceutical shop. ${ }^{7}$ However, larger shares are in fact being self-medicated or not receiving treatment at all, with the sole exception of Liberia. Once again, this is troubling in a region where CQ-resistant malaria is prevalent, especially since good antimalarial drugs are typically not available at home (see Table A4 in the Appendix), which is probably a good thing for various other reasons.

\footnotetext{
${ }^{7}$ In Kenya, based on the study of Cohen et al. (2015), many households procure drugs from drug shops instead of public facilitites.
} 


\subsection{MAIN RESULTS}

Regression results for all outcomes and three different model specifications are displayed in Table 2. In the basic-model specification (Column 1), we control for child-related variables, mother-related variables, household size, region fixed effects, and time fixed effects. The fixed effects partly capture the effects of antimalarial drug availability and health-care costs, since institutional factors vary considerably across regions and time (see Table A3 in the Appendix). The extended-model specification (Column 2) additionally controls for wealth and income at the household level via proxy variables. Finally, we supplement the extended model with variables on environmental factors to arrive at the full-model specification (Column 3). By gradually including income and environmental factors, such as access to safe water and bed net usage at night time, we aim to establish the robustness of our results with respect to accounting for the ability to pay for health services and antimalarial drugs, as well as for the likelihood that the child's fever episode is due to malaria. Since the malaria parasite is carried by mosquitoes which lay their larvae in stagnant water, we assume that a lack of safe water and sanitation is positively associated with the likelihood of malaria. Bed-net use also reduces exposure to the malaria vector.

We discuss the separate regressions by outcome variables in turn. First, concerning the probability of using any antimalarial medication, we observe for all three model specifications significantly positive coefficients for public and private hospitals, other public and private facilities, and (pharmaceutical) shops. ${ }^{8}$ Under the full-model specification, the effect is largest for other public facilities (41.91 percentage points), followed by public and private hospitals with an increased likelihood to prescribe antimalarial treatment of around 35 percentage points, compared to the self-medication category. While other private facilities and (pharmaceutical) shops are also positively and significantly associated with increased antimalarial drug use relative to self-medication, we find no difference in antimalarial drug usage rates between children who were brought to a traditional healer and children who were self-medicated.

\footnotetext{
${ }^{8}$ For the other outcome variables, the results are also robust across model specifications (Table 2). Henceforth, we focus on the results from the full-model specification. Table A2 in the Appendix presents the estimated coefficients of all the covariates in the full-model specification.
} 
Furthermore, pairwise comparisons between traditional healers and other health-care providers show that traditional healers are significantly less likely to advise the use of antimalarial drugs. Although Leonard (2003) shows that traditional healers may provide more effort in health care (and require more effort from their patients) because of the nature of contracting between healer and patient, it does not seem to translate to a higher likelihood of receiving antimalarial drugs. We find no significant differential between seeking advice at a public or a private hospital on the likelihood of using antimalarial drugs. However, compared to seeking advice at other public facilities, visits to other private facilities significantly decrease the likelihood to use antimalarial medication by 13.74 percentage points $(p$ value $=0.000)$. On the other hand, patients of other private facilities are 11.72 percentage points $(p$ value $=0.006)$ more likely to receive antimalarial medicine than febrile children whose parents sought advice at (pharmaceutical) shops.

With respect to receiving good antimalarial treatment (conditional on having received any antimalarial drug), we only observe statistically significant coefficients for public hospitals and other public facilities. Children advised by public hospitals have the greatest chance of receiving effective antimalarial drugs. Compared to self-medication, seeking advice at a public hospital [other public facility] is associated with an increased probability of taking an effective antimalarial drug by 4.89 [3.36] percentage points. At the 10-percent level of significance, the coefficients of public hospitals and other public facilities are significantly larger than the coefficients of the other health-care providers. A possible explanation is that, for Liberia and Nigeria (2008), good antimalarial drugs are free of charge in the public sector (Table A3 in the Appendix), while in the private sector, they are not. There is no significant difference between the two public providers.

As to the probability of taking CQ (conditional on having received any antimalarial drug), we find significant negative relationships for public and private hospitals, other public facilities, and (pharmaceutical) shops. The associated probability of taking CQ is lower by $8.12,8.04,6.91$, and 6.39 percentage points, respectively. These coefficients do not differ from each other in terms of statistical significance. Seeking advice of traditional healers and of "other private facility" is not associated with the type of antimalarial treatment. 
Finally, the fever regression results yield that-except for traditional healers-all health-care providers are associated with an increased likelihood of relieving fever symptoms as compared to selfmedication. Again, this points to the inefficacy of traditional healers in the context of malaria management. The estimated coefficients range from -3.26 (other public facility) to -8.87 (other private facility) percentage points. Other private facilities, public hospitals, and (pharmaceutical) shops have, in absolute terms, significantly larger coefficients than traditional healers (at the 10 percent level).

\subsection{SOCIOECONOMIC GRADIENT IN TREATMENT QUALITY}

To assess socioeconomic differences, we run separate regressions for each of the five wealth index groups ("poorest", "poorer", "middle", "richer", and "richest") as defined by the DHS. The results are presented in Table 3. The distribution of wealth within a particular country can be different from another country in our sample, but country fixed effects are included in the regression analysis to capture these differences. Across wealth quintiles, we find substantial differences in the likelihood of receiving any antimalarial drug and in the likelihood of resolving fever for various health-care providers. In contrast, we find no such heterogeneity with respect to the type (effective vs. ineffective) of antimalarial treatment conditional on any antimalarial treatment.

The equality-of-coefficients test indicates that, for all providers (including traditional healers), significant differences exist across wealth quintiles for the antimalarial drug outcome. This holds only for private hospitals in the fever regressions. It must be noted, though, that the sample sizes of each wealth quintile is much smaller for the "good antimalarial" and "chloroquine only" regressions because of the conditioning on the receipt of any antimalarial drug and the lack of data for some countries.

For the antimalarial drug outcome variable, the coefficients of all types of health-care providers (except for the traditional-healer category, where the difference is not statistically significant) are lower among the richer and richest when compared to the poorer and poorest. In terms of the regression for the likelihood of having a fever at the time of the survey, we also find significant differences in the provider coefficients between the poorest and richest quintiles for public hospital, private hospital 
(both at the 10-percent significane level), and other private facilities. The larger associations, in absolute terms, are observed in the poorest wealth quintile.

We explain these socioeconomic differences by a differential in both outcomes across wealth quintiles among children who did not seek any advice (the reference group). The richest people may, for instance, be well informed about antimalarial treatments and have reserves of antimalarial drugs at home since rapid treatment of this disease is predictive of eventual success of treatment. In line with this, we observe a differential (20 and -6 percentage points) in the antimalarial usage rate and the chance to remain febrile between the richest and the poorest quintile (not displayed).

\section{NATIONAL MALARIA CONTROL STRATEGIES}

\subsection{DIFFERENCES ACROSS COUNTRIES}

There is some variation in malaria-control policies across West sub-Saharan African countries. Differences prevail concerning the type of first-line antimalarial treatment although all post-2003 policies recommend ACT. Further differences include costs of (public) health care and availability of antimalarial drugs. This section aims to shed light on the general importance of malaria-control policies for the quality of provided care by relating the treatment that febrile children receive at different healthcare providers with facets of national policies. That is, we analyze whether the benefit of visiting a certain health-care provider is related to the various institutional aspects of malaria control. The country-by-country estimation results are provided in Table 4 and Table 5.

It is evident that more formal providers (those other than traditional healers) are much more likely to provide antimalarial drugs to febrile children across all countries. However, within each country, there is some variation in how much more likely antimalarial drugs will be provided relative to self-medication. For example, in Burkina Faso, going to a public hospital is associated with a 20-percent increase in the probability of receiving an antimalarial drug compared to self-medication, but this same effect is estimated to be 60 percent in Liberia. Concerning the type of antimalarial drug, the public and private sectors in Ghana (only 2008) stand out in terms of an increased likelihood of good antimalarial 
treatment (Table 4, lower panel). In this country, public and private hospitals, other public facilties, and (pharmaceutical) shops all exhibit a significantly positive coefficient.

Heterogeneity across countries is more pronounced with regard to CQ-only treatment (Table 5, upper panel). A lower likelihood of receiving only CQ compared to self-medication is found in the public sector in Ghana, Guinea (public hospitals in both countries), Burkina Faso, Mali, and Niger (other public facilities in the three countries). In Benin, Liberia, and Nigeria, public sector patients are just as likely to take CQ as self-medicating children. In Benin and Liberia, this may be explained by relatively low overall CQ utilization rates (Tabel 1). In Nigeria, however, CQ use is very common, which is could indicate the low quality of public services but more likely because CQ was the first-line treatment in 2003.

The effectiveness of health-care providers in terms of fever relief is highest in Liberia (Table 5, lower panel). All individual health-care provider coefficients are significant and amount to more than 20 percent. Hence, irrespective of the type of provider (including, interestingly, tradtional healers), seeking advice for a febrile child at any health-care provider is strongly recommendable in Liberia. Notably, Liberia has free testing and free ACT in the public sector. In the other countries, the difference in fever relief success across health-care providers is less pronounced.

\subsection{CHANGE IN NATIONAL POLICIES OVER TIME}

For Ghana and Nigeria, we are able to use information from two waves of the DHS (2003 and 2008 for both countries). The goal of this exercise is to determine whether there were differences in the effectiveness of the different providers between the two time periods and whether these differences over time vary across the two countries. The latter will give an indication regarding the impact of different malaria-control policies because both countries implemented reforms of their national guidelines between 2003 and 2008. These two countries represent interesting cases because both had similar policies in place with CQ as first-line treatment, presumptive antialaria medication, and fee for services in 2003 but malaria control reforms-except of the introduction of ACT as first-line treatment in 2004-were different between the two countries (Table A3). The estimation results are provided in Table 6. 
Ghana demonstrated an improvement in treatment quality as compared to self-medication while Nigeria presents a rather mixed case. Considering, for instance, the likelihood of receiving antimalarial drugs, the difference between self-treatment and all health care providers except traditional healers increased substantially between the years 2003 and 2008 for Ghana. Private hospitals (from 11.19 to 51.08 percentage points) and pharmaceutical shops (from 16.82 to 39.33 percentage points) represent the most dramatic increases. In contrast, the corresponding estimates for Nigeria declined in each case. The likelihood for traditional healers to provide antimalarial drugs remains to be statistically indistinguishable from self-treatment for both countries over time.

Quality improvements of public and private hospitals as well as traditional healers can be observed with respect to the provision of CQ-only for Ghana. Ghana's achievements may be explained by the nation's effort to address CQ-resistant malaria. In fact, Ghana replaced its own Anti-Malaria Drug Policy with one that was more in line with the WHO guidelines. The latter not only required presumptive malaria treatment but also encouraged the adoption of artesunate with amodiaquine, a type of ACT. Since 2002, taxes were waived on the importation of insecticide-treated bed nets in the country. Its distribution to poorer areas of the country, in particular to pregnant women and children under five, was also subsidized by the state. According to the DHS final report on Ghana for 2008, "Implementation of the new treatment policy began in the last quarter of 2005 with countrywide training of health-care providers in both private and public sectors...The [Ghana Health Service] strongly advised caregivers of young children with signs and symptoms of malaria to access treatment at the nearest health facility."

Although a similar program was introduced in Nigeria as well (also in response to the rise of the CQ-resistant parasite), the ACT treatment in Nigeria was based on artemether with lumefantrine, as opposed to the treatment encouraged in Ghana (artesunate with amodiaquine). Although the Nigerian government has undertaken steps as well to ensure increased access to ACT, it seems that their efforts were not nearly as successful as Ghana's. 


\section{DISCUSSION AND CONCLUSION}

Our main findings are the following. First, compared to self-treatment, children who seek treatment at public and private hospitals, other public and private facilities, and (pharmaceutical) shops have a significantly higher likelihood to take any antimalarial drug at all. Going to a traditional healer is no different from self-medication. The largest correlation is found for non-hospital ("other") public facilities: government-run health centers, government field worker, and other public-sector health points are associated with an increased likelihood of antimalarial drug use by 89 percent. This is an important result since our data show that guardians of children with fever who seek advice are most likely to visit other public facilities.

At the same time, it should be noted that these treatment practices may not necessarily translate to other groups (i.e., those who are not children below five years of age). This is especially true for complicated malaria, such as those experienced by pregnant women, and malaria experienced by older children. The prevalence of malaria is highly age dependent, since children below five years are more likely to have malaria conditional on having a fever than children who are older simply because they have developed immunity to P. falciparum (unlike P. vivax, which, although less severe and associated with less complications, can recur).

With respect to receiving good antimalarial treatment (conditional on having received any antimalarial drug), we only observe significant associations for public hospitals and other public facilities. This may be explained by national and international efforts to make ACTs available on a large scale through public channels. As to the probability of taking only CQ conditional on antimalarial treatment, we find significant correlations for public and private hospitals, other public facilities, and (pharmaceutical) shops. While other private facilities such as private doctors and private maternity homes do not perform any better than self-treatment in terms of good antimalarial drug and CQ-only use, they are associated with significant fever-relief. 
We have exhausted all avenues this particular dataset allows to rule out confounding factors. First, we control for a wide range of individual, household, and environmental factors. Second, we carried out several robustness tests such as the gradual incorporation of proxy variables for income and the likelihood that the fever episode is due to malaria into our econometric model. Nevertheless, we do not directly observe whether a child actually has malaria. If malaria is associated with a higher chance of both seeking advice at, for instance, public health centers and (effective) antimalarial medication, effect estimates can be biased. ${ }^{9}$ Indeed, we do not have information on differential treatment practices for laboratory- or RDT-confirmed malaria cases. Given these considerations, the results should certainly be interpreted with caution, although there are a number of reasons why we are less concerned about selection while acknowledging its likely presence.

First, the presumptive treatment regimen makes these associations irrelevant because all febrile children should have received antimalarial medication in any case. The fundamental issue is the ability of health-care providers to comply with national and international guidelines, which may change in response to the declining prevalence of P. falciparum malaria in sub-Saharan Africa. When these guidelines change, high-quality providers can be expected to rapidly comply while low-quality providers may never do. Second, the inclusion of malaria proxy variables such as indicators for access to safe water and bed-net usage at night time only marginally changed the provider coefficients. If differences in the likelihood of being exposed to malaria were the main factors that influenced the provider choice, then we expect larger differences between estimates from the model with and without these proxy variables for malaria exposure. Third, we find similar quality differences across health-care providers when we restrict the sample to children who received any antimalarial medication and look at the type of antimalarial drug used. By administering antimalarial drugs to these children, providers make their assessment of a malaria case explicit, irrespectively of whether it is based on a diagnostic test result or presumptive treatment. Administering first-line antimalarial drugs is then a definite signal of good quality (and CQ-only use, conversely, a signal of bad quality).

9 This is the "self-selection by illness condition" to which Leonard (2003) alludes. 
Cross-country comparisons of the estimated health-care provider coefficients on antimalarial drug use and the fever outcome variable reveal substantial heterogeneity in the quality of care across countries. Variation across insititutional frameworks allows us to assess whether, conditional on regional fixed effects within a country, unobserved price elasticities and drug availability influence our results. We do not find any strong indication of this in the data. For instance, Liberia and Nigeria (2008) are two countries where both advice and antimalarial drugs are free of charge in the public sector. In Liberia, public facilities perform above average in terms of treatment quality (except good antimalarial drug use). In Nigeria, they achieve average results. If public providers actually exert no influence on antimalarial drug use and our results are mainly driven by price elasticities, we should not find considerable differences for public sector entities in these countries because the absence of health-care fees eliminates the effect of the price of health services. In contrast, if drug availability is an important unobserved factor, we should observe higher-rather than lower-coefficients for public providers in Nigeria (where drug availability is much better).

Our results indicate that private-sector treatment (including pharmaceutical shops) is not any better than self-medication in terms of first-line compliance. For these providers, we know that they have a higher likelihood of prescribing some antimalarial drug but it is not exclusively CQ. However, it is also not a combination therapy. Therefore, it must be the case that these providers are prescribing antimalarial drugs as monotherapies or not according to the national guidelines. This has profound negative implications for the development of drug-resistant parasites. The WHO (2006b) recommends that artemisinin should not be allowed to be marketed as monotherapies precisely for this reason.

It is obvious that a variety of antimalarial drugs are currently being provided in the market, which also has implications for the development of drug-resistant parasites. There is some evidence, based on the experience of Malawi, that a reduction in drug pressure could increase the susceptibility of P. falciparum to older-generation drugs (Flegg et al., 2013). Note that Malawi transitioned from CQ to SP in 1993 and stayed with that first-line treatment for uncomplicated malaria until 2007, when it followed most other countries by adopting ACTs as the first-line drug. For more than a decade, CQ was not widely administered in the country. Now, there is evidence that CQ-susceptible P. falciparum has re- 
emerged (Frosch et al., 2011). If nations which have adopted ACT as the first-line drug manage to completely remove CQ from the market, there may be an opportunity in the future to reintroduce it as the CQ-susceptible variant parasite returns, implying that drugs may be cycled in a regime of changing clinical guidelines.

This points to the need for programs to improve private sector access to arteminisin-based combination therapies (ACT). The Affordable Medicines Facility-malaria (AMFm) managed by the Global Fund to Fight AIDS, Tuberculosis and Malaria, for instance, represents an effective way to close the ACT-availability gap between the public and private sectors. Based on the initial idea of Arrow (2004), AMFm works by negotiating with drug manufacturers to reduce the price of ACT, and to require sales-price parity between the public and private sectors. As Cohen et al. (2015) note, "fewer than 15 percent of African children with malaria were treated with ACTs." Tougher et al. (2012) show in several pilot studies that there were large increases in ACT availability and market share driven mainly by changes in the private for-profit sector. This is an important initiative because "CQ and SP are up to 25 times less expensive than an ACT" (Flegg et al, 2013:863). Even traditional healers "command fees exceeding the average treatment cost at most modern practitioners" (Leonard, 2003).

However, there is an acknowledged tradeoff when choosing to subsidize ACTs especially when clinical confirmation of the presence of malaria is not that common. Since ACTs may be administered to patients who do not have malaria, the scope for heterogeneous returns is much larger. Demand for the drug may therefore bifurcate: those with higher returns will increase their demand for the treatment while those with lower returns will demand less (Cohen et al., 2015). For those receiving the treatment even without having malaria, their returns are low, and this could negatively impact on the adoption of the new therapies (Adhvaryu, 2014). Ultimately, we could end up in a situation of overtreatment under a regime of presumptive treatment, where the recovery of those without malaria is delayed, resources allocated for actual malaria are wasted, and drug-resistant parasites are the norm (Cohen et al., 2015).

We are concerned that such instruments like AMFm fail to reach the poorest unless they come with effective measures to increase professional-advice-seeking rates. In line with our data, Filmer 
(2005) finds the lowest advice-seeking rates among the poorest. We observe that, within the selftreatment group, the poorest are also those who have the lowest likelihood to take any antimalarial drug (and, conditional on taking such drugs, they have the highest likelihood to take the ineffective ones). We therefore recommend complementing national and international efforts directed towards the availability of ACTs with measures to improve health-service use among the poor.

In addition, the shift to a "test and treat" regime should be facilitated by making RDTs widely available coupled with appropriate training for their use. Cohen et al. (2015) show that subsidizing RDTs by up to 85 percent or more and making them more available "doubles the rate at which illnesses are tested for malaria." While presumptive treatment was useful when malaria was highly prevalent, the disease is now in decline, and the balance is shifting to overtreatment in certain situations. If confirmatory tests can be made more available, advocating for a presumptive-treatment regime will become a less tenable position to take.

As possible policy instruments, demand-side and supply-side performance-based incentive schemes have been suggested in the literature (e.g., Eichler et al., 2009). Rewarding the poorest families for seeking care for their febrile children and rewarding providers for the use of rapid diagnostic tests and (conditional on a positive test result) to administer ACTs are obvious candidates for such interventions. Performance-based provider incentives would have the attractive feature of encouraging higher treatment-seeking rates. There are several ways a provider may be able to increase the use of its services. Service quality is certainly an important lever, but we have to be able to measure quality first. 


\section{LITERATURE}

Adhvaryu, A. (2014): "Learning, Misallocation, and Technology Adoption: Evidence from New Malaria Therapy in Tanzania”. The Review of Economic Studies 81(4):1331-1365.

Angrist, J.D. and J.-S. Pischke (2009): Mostly Harmless Econometrics: An Empiricist's Companion. Princeton, NJ: Princeton University Press.

Arrow, K. (2004): "Saving Lives, Buying Time: Economics of Malaria Drugs in an Age of Resistance". Washington, DC: National Academies Press

Berman, P. and R. Bitran (2011): "Health Systems Analysis for Better Health Systems Strengthening." HNP Discussion Paper, The World Bank, Washington, D.C.

Brugha, R. and A. Zwi (1998): "Improving the Quality of Private Sector Delivery of Public Health Services: Challenges and Strategies". Health Policy and Planning 13(2):107-120.

Cohen, J., P. Dupas, and S. Schaner (2015): “Price Subsidies, Diagnostic Tests, and Targeting of Malaria Treatment: Evidence from a Randomized Controlled Trial”. The American Economic Review 105(2):609-645.

Collier, P., S. Dercon, and J. Mackinnon (2003): "Density versus Quality in Health Care Provision: Using Household Data to Make Budgetary Choices in Ethiopia". The World Bank Economic Review 16(3): 425-448.

D'Acremont, V., C. Lengeler, H. Mshinda, D. Mtasiwa, M. Tanner, and B. Genton (2009): “Time To Move from Presumptive Malaria Treatment to Laboratory-Confirmed Diagnosis and Treatment in African Children with Fever" PLoS Medicine 6(1):e252.

Das, J. and J. Hammer (2005): "Which doctor? Combining vignettes and item response to measure clinical competence". Journal of Development Economics 78(2): 348-338.

Das, J. and J. Hammer (2007): "Money for nothing: The dire straits of medical practice in Delhi, India." Journal of Development Economics 83(1): 1-36.

Ebong, O. O., E. O. Asuquo, C. A. Nwauche, I. M. Siminialayi, I. H. Ogbuehi, and M. F. Ajienka (2012): "Antimalarial treatment by health care providers in Port Harcourt, Nigeria." Malaria Journal 11(Suppl. 1).

Eichler, R., and R. Levine (2009): "Performance Incentives for Global Health: Potential and Pitfalls". Washington, DC: Center for Global Development.

Filmer, D. (2005): "Fever and its Treatment among the More and Less Poor in Sub-Saharan Africa". Health Policy and Planning 20(6): 337-346.

Flegg, J.A., C.J.E. Metcalf, M. Gharbi, M. Venkatesan, T. Shewchuk, C.H. Siblcy, and P.J. Guerin (2013): "Trends in Antimalarial Drug Use in Africa". American Journal of Tropical Medicine and Hygiene 89(5):857-865. 
Frosch, A. E. P., M. Venkatesan, and M. K. Laufer (2011): "Patterns of chloroquine use and resistance in sub-Saharan Africa: a systematic review of household survey and molecular data”. Malaria Journal 10(116).

Graz, B., M. Willcox, T. Szeless, and A. Rougemont (2011): “'Test and treat' or presumptive treatment for malaria in high transmission situations? A reflection on the latest WHO guidelines". Malaria Journal 10:136.

Hesdorffer, Dale C., J. Ghajar, and L. Iacono (2002): "Predictors of Compliance with the Evidence-Based Guidelines for Traumatic Brain Injury Care: A Survey of United States Trauma Centers". The Journal of Trauma, Injury, Infection, and Critical Care 52(6):1202-1209.

Karbach, U., I. Schubert, J. Hagemeister, N. Ernstmann, H. Pfaff, H.-W. Höpp (2011): “Physicians' Knowledge of and Compliance with Guidelines: An Exploratory Study in Cardioavscular Diseases". Deutsches Ärzteblatt International 108(5):61-69.

Lechner, M. (2008): "A Note on the Common Support Problem in Applied Evaluation Studies". Annals of Economics and Statistics / Annales d'Économie et de Statistique (91/92): 217-235.

Leonard, K.L. (2003): "African traditional healers and outcome-contingent contracts in health care". Journal of Development Economics 71:1-22.

McCombie, S. C. (1996): “Treatment seeking for malaria: a review of recent research". Social Science and Medicine 34(6): 933-945.

Ménard, D., C. Barnadas, C. Bouchier, C. Henry-Halldin, L.R. Gray, A. Ratsimbasoa, V. Thonier, J.-F. Carod, O. Domarle, Y. Colin, O. Bertrand, J. Picot, C.L. King, B.T. Grimberg, O. Mercereau-Puijalon, P.A. Zimmerman (2010): "Plasmodium vivax clinical malaria is commonly observed in Duffy-negative Malagasy people". Proceedings of the National Academy of Sciences of the United States of America 107(13):5967-5971.

Nshakira, N., M. Kristensen, F. Ssali, and S. Reynolds Whyte (2002): “Appropriate treatment of malaria? Use of antimalarial drugs for children's fevers in district medical units, drug shops and homes in eastern Uganda". Tropical Medicine \& International Health 7(4):309-316.

Ofori-Adjei, D. and D.K. Arhinful (1996): "Effect of training on the clinical management of malaria by medical assistants in Ghana". Social Science \& Medicine 42(8):1169-1176.

Onwujekwe, O., B. Uzochukwu, N. Dike, N. Uguru, E. Nwobi, and E. Shu (2009): "Malaria treatment perceptions, practices and influences on provider behaviour: comparing hospitals and nonhospitals in south-east Nigeria". Malaria Journal 8(246).

RBM (2005): “Global strategic plan: Roll back malaria 2005-2015”. Roll Back Malaria Partnership, Geneva, Switzerland.

Sekhon, R., N. Aminjavahery, C.N. Davis Jr., M.J. Roswarski, and C. Robinette (2013): “Compliance with Opioid Treatment Guidelines for Chronic Non-Cancer Pain (CNCP) in Primary Care at a Veterans Affairs Medical Center (VAMC)". Pain Medicine 14(10):1548-1556. 
Smith, Lucy A., Jane Bruce, Lamine Gueye, Anthony Helou, Rodio Diallo, Babacar Gueye, Caroline Jones, and Jayne Webster (2010): "From fever to antimalarial: the treatment-seeking process in rural Senegal”. Malaria Journal 9(333).

Tavrow, P., J. Shabahang, and S. Makama (2003): "Vendor-to-vendor education to improve malaria treatment by private drug outlets in Bungoma District, Kenya". Malaria Journal 2(10).

Tougher, S., the ACTwatch Group, Y. Ye, J. H. Amuasi, I. A. Kourgueni, R. Thomson, C. Goodman, A. G. Mann, R. Ren, B. A. Willey, C. A. Adegoke, A. Amin, D. Ansong, K. Bruxvoort, D. A. Diallo, G. Diap, C. Festo, B. Johanes, E. Juma, A. Kalolella, O. Malam, B. Mberu, S. Ndiaye, S. B. Nguah, M. Seydou, M. Taylor, S. Torres Rueda, M. Wamukoya, F. Arnold, and K. Hanson (2012): "Effect of the Affordable Medicines Facility-malaria (AMFm) on the availability, price, and market share of quality-assured artemisinin-based combination therapies in seven countries: a before-and-after analysis of outlet survey data". The Lancet 380(9857): 1916-1926.

Ughasoro, M.D., C.C. Okoli, and B.S.C. Uzochukwu (2013): "Qualitative study of presumptive treatment of childhood malaria in third tier tertiary hospitals in southeast Nigeria: A focus group and indepth study". Malaria Journal 12:436.

WHO (2003): "Assessment and Monitoring of Antimalarial Drug Efficacy for the Treatment of Uncomplicated Falciparum Malaria. World Health Organization, Geneva, Switzerland.

WHO (2006a): "Guidelines for the treatment of Malaria". World Health Organization, Geneva, Switzerland.

WHO (2006b): "WHO briefing on Malaria Treatment Guidelines and artemisinin monotherapies". World Health Organization, Geneva, Switzerland.

WHO (2010): “Guidelines for the treatment of malaria”. $2^{\text {nd }}$ edition. World Health Organization. Geneva, Switzerland.

WHO (2008): “World Malaria Report 2008”. World Health Organization. Geneva, Switzerland.

WHO (2010): “World Malaria Report 2010”. World Health Organization. Geneva, Switzerland.

WHO (2012): “World Malaria Report 2012”. World Health Organization. Geneva, Switzerland.

WHO (2014a): “Malaria Fact Sheet No. 94”. World Health Organization. Geneva, Switzerland.

WHO (2014b): “World Malaria Report 2014”. World Health Organization. Geneva, Switzerland.

WHO (2015): “Guidelines for the treatment of malaria." 3 ${ }^{\text {rd }}$ edition. World Health Organization. Geneva, Switzerland.

Williams, H.A. and C.O.H. Jones (2004): "A critical review of behavioral issues related to malaria control in sub-Saharan Africa: what contributions have social scientists made?" Social Science \& Medicine 59(3):501-523. 
Wooldridge, J.M. (2010): Econometric Analysis of Cross Section and Panel Data. Cambridge, MA: MIT Press. 
TABLE 1

MEANS OF OUTCOME AND TREATMENT VARIABLES BY COUNTRY

\begin{tabular}{|c|c|c|c|c|c|c|c|c|}
\hline & Burkina Faso & Benin & Ghana & Guinea & Liberia & Mali & Nigeria & Niger \\
\hline Antimalarial & 0.5345 & 0.5734 & 0.5765 & 0.4361 & 0.5731 & 0.3588 & 0.3868 & 0.3638 \\
\hline Chloroquine only & 0.4881 & 0.1854 & 0.1982 & 0.2303 & 0.1343 & 0.3756 & 0.3398 & 0.4513 \\
\hline Has fever now & 0.2672 & 0.2430 & 0.3041 & 0.3219 & 0.2801 & 0.3461 & 0.3500 & 0.1929 \\
\hline Other public facility & 0.3051 & 0.2316 & 0.1778 & 0.2695 & 0.2801 & 0.2579 & 0.1448 & 0.2950 \\
\hline Private hospital & 0.0041 & 0.0420 & 0.0593 & 0.0087 & 0.1219 & 0.0111 & 0.0587 & 0.0128 \\
\hline Other private facility & 0.0108 & 0.0572 & 0.0155 & 0.0225 & 0.0634 & 0.0227 & 0.1649 & 0.1344 \\
\hline Pharmacy/shop & 0.0823 & 0.1123 & 0.2053 & 0.1703 & 0.1361 & 0.0377 & 0.2228 & 0.1503 \\
\hline Traditional healer & 0.0575 & 0.1728 & 0.0455 & 0.0892 & 0.0727 & 0.2085 & 0.0308 & 0.0282 \\
\hline
\end{tabular}

NOTES: In calculating the share of children who took good antimalarial drugs and chloroquine, the observations are restricted to those who have taken any antimalarial drug. Hence, the numbers of observations above do not apply for the rows "Good antimalarial" and "Chloroquine only". We have no information available on whether good antimalarial drugs were provided in Burkina Faso, Guinea, Mali, and Niger. For Ghana and Nigeria, good antimalarial drug refers to the year 2008 only.

SOURCE: Authors' calculations based on the DHS. 
TABLE 2

LINEAR PROBABILITY MODEL ESTIMATION RESULTS FOR DIFFERENCES IN THE TREATMENT PRACTICE ACROSS HEALTH-CARE PROVIDERS

\begin{tabular}{|c|c|c|c|}
\hline & Basic model & Extended model & Full model \\
\hline \multicolumn{4}{|l|}{ Any antimalarial } \\
\hline \multirow[t]{2}{*}{ Public hospital } & $0.3573 * * *$ & $0.3505^{* * *}$ & $0.3499 * * *$ \\
\hline & $(0.0156)$ & $(0.0157)$ & $(0.0157)$ \\
\hline \multirow[t]{2}{*}{ Other public facility } & $0.4273 * * *$ & $0.4200 * * *$ & $0.4191 * * *$ \\
\hline & $(0.0088)$ & $(0.0089)$ & $(0.0089)$ \\
\hline \multirow[t]{2}{*}{ Private hospital } & $0.3541 * * *$ & $0.3483 * * *$ & $0.3474 * * *$ \\
\hline & $(0.0186)$ & $(0.0187)$ & $(0.0187)$ \\
\hline \multirow[t]{2}{*}{ Other private facility } & $0.2866^{* * *}$ & $0.2820 * * *$ & $0.2817 * * *$ \\
\hline & $(0.0145)$ & $(0.0145)$ & $(0.0145)$ \\
\hline \multirow[t]{2}{*}{ Pharmacy/shop } & $0.1679 * * *$ & $0.1654^{* * *}$ & $0.1645^{* * *}$ \\
\hline & $(0.0114)$ & $(0.0114)$ & $(0.0114)$ \\
\hline \multirow[t]{2}{*}{ Traditional healer } & -0.0095 & -0.0081 & -0.0079 \\
\hline & $(0.0128)$ & $(0.0128)$ & $(0.0127)$ \\
\hline Observations & 18069 & 18069 & 18069 \\
\hline \multicolumn{4}{|l|}{ Good antimalarial } \\
\hline \multirow[t]{2}{*}{ Public hospital } & $0.0499 * *$ & $0.0485^{* *}$ & $0.0489 * *$ \\
\hline & $(0.0185)$ & $(0.0185)$ & $(0.0185)$ \\
\hline \multirow[t]{2}{*}{ Other public facility } & $0.0335 * * *$ & $0.0335 * * *$ & $0.0336 * * *$ \\
\hline & $(0.0092)$ & $(0.0092)$ & $(0.0092)$ \\
\hline \multirow[t]{2}{*}{ Private hospital } & 0.0062 & 0.0043 & 0.0054 \\
\hline & $(0.0161)$ & $(0.0160)$ & $(0.0160)$ \\
\hline \multirow[t]{2}{*}{ Other private facility } & -0.0046 & -0.0043 & -0.0038 \\
\hline & (0.0109) & (0.0109) & (0.0109) \\
\hline \multirow[t]{2}{*}{ Pharmacy/shop } & -0.0072 & -0.0079 & -0.0083 \\
\hline & $(0.0138)$ & (0.0139) & $(0.0139)$ \\
\hline \multirow[t]{2}{*}{ Traditional healer } & 0.0060 & 0.0063 & 0.0059 \\
\hline & $(0.0118)$ & $(0.0114)$ & $(0.0115)$ \\
\hline Observations & 4305 & 4305 & 4305 \\
\hline \multicolumn{4}{|l|}{ Chloroquine only } \\
\hline \multirow[t]{2}{*}{ Public hospital } & $-0.0934 * * *$ & $-0.0851 * * *$ & $-0.0812 * * *$ \\
\hline & $(0.0190)$ & $(0.0190)$ & (0.0189) \\
\hline \multirow[t]{2}{*}{ Other public facility } & $-0.0751 * * *$ & $-0.0716 * * *$ & $-0.0691 * * *$ \\
\hline & $(0.0133)$ & (0.0133) & $(0.0133)$ \\
\hline \multirow[t]{2}{*}{ Private hospital } & $-0.0959 * * *$ & $-0.0833 * * *$ & $-0.0804 * * *$ \\
\hline & $(0.0208)$ & (0.0209) & $(0.0208)$ \\
\hline \multirow[t]{2}{*}{ Other private facility } & -0.0067 & -0.0036 & -0.0013 \\
\hline & $(0.0206)$ & $(0.0205)$ & $(0.0205)$ \\
\hline Pharmacy/shop & $-0.0676 * * *$ & $-0.0677 * * *$ & $-0.0639 * * *$ \\
\hline & $(0.0175)$ & $(0.0175)$ & $(0.0174)$ \\
\hline Traditional healer & -0.0106 & -0.0121 & -0.0098 \\
\hline & $(0.0221)$ & $(0.0221)$ & $(0.0221)$ \\
\hline Observations & 8593 & 8593 & 8593 \\
\hline Has fever now & & & \\
\hline Public hospital & $-0.0616^{* * *}$ & $-0.0582 * * *$ & $-0.0570 * * *$ \\
\hline & $(0.0151)$ & $(0.0152)$ & $(0.0152)$ \\
\hline Other public facility & $-0.0349 * * *$ & $-0.0337 * * *$ & $-0.0326 * * *$ \\
\hline & $(0.0091)$ & $(0.0091)$ & $(0.0091)$ \\
\hline Private hospital & $-0.0535^{* *}$ & $-0.0480 * *$ & $-0.0470 *$ \\
\hline & $(0.0184)$ & $(0.0185)$ & $(0.0185)$ \\
\hline Other private facility & $-0.0907 * * *$ & $-0.0895^{* * *}$ & $-0.0887^{* * *}$ \\
\hline & $(0.0140)$ & $(0.0140)$ & $(0.0140)$ \\
\hline Pharmacy/shop & $-0.0481 * * *$ & $-0.0470 * * *$ & $-0.0462 * * *$ \\
\hline & $(0.0110)$ & $(0.0110)$ & $(0.0110)$ \\
\hline Traditional healer & -0.0216 & -0.0220 & -0.0218 \\
\hline & (0.0129) & (0.0129) & (0.0129) \\
\hline Observations & 18069 & 18069 & 18069 \\
\hline
\end{tabular}


TABLE 3: EstimATION RESULtS BY WEALTH INDEX

\begin{tabular}{|c|c|c|c|c|c|}
\hline & Poorest & Poorer & Middle & Richer & Richest \\
\hline \multicolumn{6}{|l|}{ Antimalarial } \\
\hline \multirow[t]{2}{*}{ Public hospital } & $0.3955^{* * *}$ & $0.4849 * * *$ & $0.3712 * * *$ & $0.2973^{* * *}$ & $0.1473^{* * *}$ \\
\hline & $(0.0392)$ & $(0.0362)$ & $(0.0364)$ & $(0.0331)$ & $(0.0366)$ \\
\hline \multirow[t]{2}{*}{ Other public facility } & $0.4867 * * *$ & $0.4576 * * *$ & $0.4132 * * *$ & $0.3991 * * *$ & $0.2504 * * *$ \\
\hline & $(0.0198)$ & $(0.0192)$ & $(0.0189)$ & $(0.0201)$ & $(0.0260)$ \\
\hline \multirow[t]{2}{*}{ Private hospital } & $0.4589 * * *$ & $0.4272 * * *$ & $0.3482 * * *$ & $0.3298 * * *$ & $0.1704 * * *$ \\
\hline & $(0.0520)$ & $(0.0537)$ & $(0.0452)$ & $(0.0356)$ & $(0.0382)$ \\
\hline \multirow[t]{2}{*}{ Other private facility } & $0.3109 * * *$ & $0.3719 * * *$ & $0.2657^{* * *}$ & $0.2131 * * *$ & $0.1451 * * *$ \\
\hline & $(0.0294)$ & $(0.0303)$ & $(0.0324)$ & $(0.0349)$ & $(0.0405)$ \\
\hline \multirow[t]{2}{*}{ Pharmacy/shop } & $0.2073 * * *$ & $0.2187 * * *$ & $0.1472 * * *$ & $0.1335^{* * *}$ & -0.0026 \\
\hline & $(0.0211)$ & $(0.0233)$ & $(0.0262)$ & $(0.0284)$ & $(0.0356)$ \\
\hline \multirow[t]{2}{*}{ Traditional healer } & 0.0251 & 0.0135 & $-0.0840^{* *}$ & -0.0066 & -0.0219 \\
\hline & (0.0229) & $(0.0254)$ & $(0.0266)$ & $(0.0349)$ & $(0.0490)$ \\
\hline Observations & 4127 & 3937 & 3853 & 3563 & 2589 \\
\hline \multicolumn{6}{|l|}{ Good antimalarial } \\
\hline \multirow[t]{2}{*}{ Public hospital } & 0.0497 & 0.0709 & 0.0122 & 0.0561 & 0.0798 \\
\hline & $(0.0650)$ & $(0.0364)$ & $(0.0379)$ & $(0.0347)$ & $(0.0494)$ \\
\hline \multirow[t]{2}{*}{ Other public facility } & 0.0098 & $0.0692 * * *$ & 0.0349 & 0.0261 & $0.0651^{*}$ \\
\hline & $(0.0206)$ & $(0.0200)$ & $(0.0214)$ & $(0.0191)$ & $(0.0304)$ \\
\hline \multirow[t]{2}{*}{ Private hospital } & -0.0022 & 0.0138 & -0.0400 & 0.0099 & 0.0399 \\
\hline & $(0.0444)$ & $(0.0478)$ & $(0.0412)$ & $(0.0313)$ & $(0.0366)$ \\
\hline \multirow[t]{2}{*}{ Other private facility } & -0.0373 & 0.0052 & -0.0178 & 0.0094 & -0.0044 \\
\hline & $(0.0236)$ & $(0.0252)$ & $(0.0237)$ & $(0.0260)$ & $(0.0255)$ \\
\hline \multirow[t]{2}{*}{ Pharmacy/shop } & -0.0476 & $0.0632^{*}$ & -0.0536 & 0.0258 & -0.0021 \\
\hline & $(0.0281)$ & $(0.0317)$ & $(0.0375)$ & $(0.0302)$ & $(0.0321)$ \\
\hline \multirow[t]{2}{*}{ Traditional healer } & -0.0303 & 0.0197 & 0.0156 & 0.0378 & -0.0356 \\
\hline & $(0.0291)$ & $(0.0239)$ & $(0.0237)$ & $(0.0237)$ & $(0.0301)$ \\
\hline Observations & 823 & 909 & 981 & 972 & 620 \\
\hline \multicolumn{6}{|l|}{ Chloroquine only } \\
\hline \multirow[t]{2}{*}{ Public hospital } & $-0.1529 * *$ & -0.0190 & $-0.1669 * * *$ & $-0.0794 *$ & -0.0109 \\
\hline & $(0.0555)$ & $(0.0512)$ & $(0.0427)$ & $(0.0384)$ & (0.0399) \\
\hline \multirow[t]{2}{*}{ Other public facility } & -0.0600 & $-0.0819 *$ & $-0.0694^{*}$ & $-0.0889 * *$ & -0.0277 \\
\hline & $(0.0342)$ & $(0.0324)$ & $(0.0286)$ & $(0.0276)$ & $(0.0319)$ \\
\hline \multirow[t]{2}{*}{ Private hospital } & -0.1132 & -0.0695 & -0.0833 & $-0.1457 * * *$ & -0.0244 \\
\hline & $(0.0714)$ & $(0.0644)$ & $(0.0525)$ & $(0.0365)$ & $(0.0421)$ \\
\hline Other private facility & -0.0347 & 0.0765 & -0.0006 & -0.0717 & -0.0209 \\
\hline & $(0.0503)$ & $(0.0478)$ & $(0.0469)$ & $(0.0440)$ & $(0.0479)$ \\
\hline Pharmacy/shop & -0.0595 & -0.0743 & $-0.0792 *$ & $-0.0916^{*}$ & 0.0113 \\
\hline & $(0.0438)$ & $(0.0409)$ & $(0.0385)$ & $(0.0364)$ & $(0.0455)$ \\
\hline Traditional healer & -0.0471 & 0.0847 & -0.0087 & -0.0057 & -0.0214 \\
\hline & $(0.0491)$ & $(0.0502)$ & $(0.0494)$ & $(0.0486)$ & $(0.0584)$ \\
\hline Observations & 1531 & 1689 & 1887 & 1964 & 1522 \\
\hline Has fever now & & & & & \\
\hline Public hospital & $-0.0811 *$ & -0.0532 & $-0.0737^{*}$ & $-0.0838^{* *}$ & 0.0159 \\
\hline & $(0.0397)$ & $(0.0386)$ & $(0.0372)$ & $(0.0312)$ & $(0.0323)$ \\
\hline Other public facility & $-0.0525^{*}$ & -0.0269 & -0.0121 & -0.0243 & -0.0262 \\
\hline & $(0.0206)$ & $(0.0200)$ & $(0.0203)$ & $(0.0209)$ & $(0.0231)$ \\
\hline Private hospital & 0.1146 & -0.0903 & -0.0752 & $-0.0871^{*}$ & -0.0070 \\
\hline & $(0.0611)$ & $(0.0514)$ & $(0.0452)$ & $(0.0361)$ & $(0.0344)$ \\
\hline Other private facility & $-0.1324 * * *$ & $-0.0665^{*}$ & $-0.0968^{* *}$ & $-0.0817^{*}$ & -0.0339 \\
\hline & $(0.0292)$ & $(0.0312)$ & $(0.0311)$ & $(0.0334)$ & $(0.0367)$ \\
\hline Pharmacy/shop & -0.0214 & $-0.0600 *$ & $-0.0614^{*}$ & $-0.0564 *$ & -0.0202 \\
\hline & $(0.0220)$ & $(0.0233)$ & $(0.0252)$ & $(0.0266)$ & $(0.0302)$ \\
\hline Traditional healer & -0.0210 & -0.0006 & -0.0215 & -0.0216 & -0.0056 \\
\hline & $(0.0247)$ & $(0.0270)$ & $(0.0283)$ & $(0.0321)$ & $(0.0422)$ \\
\hline Observations & 4127 & 3937 & 3853 & 3563 & 2589 \\
\hline
\end{tabular}


NOTES: Regression results are based on the full model specification. The reference category is self-medication. ${ }^{*}$ significant at $5 \%$, ** significant at $1 \%, * * *$ significant at $0.1 \%$. Robust standard errors are in parentheses. We have no information available on whether good antimalarial drugs were provided in Burkina Faso, Guinea, Mali, and Niger. For Ghana and Nigeria, good antimalarial drug refers to the year 2008 only.

SOURCE: Authors' calculations based on the DHS. 
TABLE 4

PROVIDER DIFFERENCES BY COUNTRY (ANTIMALARIAL)

\begin{tabular}{|c|c|c|c|c|c|c|c|c|}
\hline & Burkina Faso & Benin & Ghana & Guinea & Liberia & Mali & Nigeria & Niger \\
\hline \multicolumn{9}{|l|}{ Antimalarial } \\
\hline Public hospital & $\begin{array}{c}0.2077^{* *} \\
(0.0718)\end{array}$ & $\begin{array}{c}0.2499 * * * \\
(0.0466)\end{array}$ & $\begin{array}{c}0.3547^{* * *} \\
(0.0402)\end{array}$ & $\begin{array}{c}0.5685^{* * *} \\
(0.0645)\end{array}$ & $\begin{array}{c}0.6023 * * * \\
(0.0423)\end{array}$ & $\begin{array}{c}0.3814^{* * *} \\
(0.1148)\end{array}$ & $\begin{array}{c}0.3000^{* * *} \\
(0.0257)\end{array}$ & $\begin{array}{c}0.3004^{* * *} \\
(0.0813)\end{array}$ \\
\hline Other public facility & $\begin{array}{c}0.3552^{* * *} \\
(0.0207)\end{array}$ & $\begin{array}{c}0.4088^{* * *} \\
(0.0191)\end{array}$ & $\begin{array}{c}0.2749 * * * \\
(0.0422)\end{array}$ & $\begin{array}{c}0.5317^{* * *} \\
(0.0284)\end{array}$ & $\begin{array}{c}0.4976^{* * *} \\
(0.0348)\end{array}$ & $\begin{array}{c}0.4229^{* * *} \\
(0.0288)\end{array}$ & $\begin{array}{c}0.4151^{* * *} \\
(0.0224)\end{array}$ & $\begin{array}{c}0.5398^{* * *} \\
(0.0263)\end{array}$ \\
\hline Private hospital & $\begin{array}{c}0.5441^{* * *} \\
(0.0433)\end{array}$ & $\begin{array}{c}0.2618^{* * *} \\
(0.0372)\end{array}$ & $\begin{array}{c}0.2804^{* * *} \\
(0.0697)\end{array}$ & $\begin{array}{c}0.5640 * * * \\
(0.1231)\end{array}$ & $\begin{array}{c}0.5472^{* * *} \\
(0.0456)\end{array}$ & $\begin{array}{c}0.3591^{* *} \\
(0.1217)\end{array}$ & $\begin{array}{c}0.3494^{* * *} \\
(0.0324)\end{array}$ & $\begin{array}{c}0.3172^{* *} \\
(0.1081)\end{array}$ \\
\hline Other private facility & $\begin{array}{c}0.0639 \\
(0.1028)\end{array}$ & $\begin{array}{c}0.3752^{* * *} \\
(0.0285)\end{array}$ & $\begin{array}{c}0.1489 \\
(0.1239)\end{array}$ & $\begin{array}{c}0.3366^{* * *} \\
(0.0905)\end{array}$ & $\begin{array}{c}0.5429^{* * *} \\
(0.0541)\end{array}$ & $\begin{array}{l}0.2165^{*} \\
(0.0865)\end{array}$ & $\begin{array}{c}0.2607^{* * *} \\
(0.0226)\end{array}$ & $\begin{array}{c}0.2340^{* * *} \\
(0.0340)\end{array}$ \\
\hline Pharmacy/shop & $\begin{array}{c}0.1461^{* * *} \\
(0.0364)\end{array}$ & $\begin{array}{c}0.0311 \\
(0.0279)\end{array}$ & $\begin{array}{c}0.2343^{* * *} \\
(0.0417)\end{array}$ & $\begin{array}{c}0.2631^{* * *} \\
(0.0368)\end{array}$ & $\begin{array}{c}0.3683^{* * *} \\
(0.0446)\end{array}$ & $\begin{array}{c}0.1995^{* *} \\
(0.0616)\end{array}$ & $\begin{array}{c}0.1917^{* * *} \\
(0.0193)\end{array}$ & $\begin{array}{c}0.1318^{* * *} \\
(0.0322)\end{array}$ \\
\hline Traditional Healer & $\begin{array}{c}-0.1585 * * * \\
(0.0363)\end{array}$ & $\begin{array}{c}0.0113 \\
(0.0238)\end{array}$ & $\begin{array}{c}0.0326 \\
(0.0698)\end{array}$ & $\begin{array}{c}-0.0869^{*} \\
(0.0377)\end{array}$ & $\begin{array}{l}0.1266^{*} \\
(0.0520)\end{array}$ & $\begin{array}{c}0.0263 \\
(0.0284)\end{array}$ & $\begin{array}{l}-0.0603 \\
(0.0317)\end{array}$ & $\begin{array}{c}0.0708 \\
(0.0569)\end{array}$ \\
\hline Observations & 2482 & 3661 & 1144 & 1438 & 1372 & 1710 & 4413 & 1849 \\
\hline Good antimalarial & & & & & & & & \\
\hline Public hospital & - & $\begin{array}{c}0.0094 \\
(0.0098)\end{array}$ & $\begin{array}{l}0.2957^{*} \\
(0.1457)\end{array}$ & - & $\begin{array}{c}0.0302 \\
(0.0636)\end{array}$ & - & $\begin{array}{c}0.0556 \\
(0.0313)\end{array}$ & - \\
\hline Other public facility & - & $\begin{array}{c}0.0148^{* * *} \\
(0.0044)\end{array}$ & $\begin{array}{l}0.3561^{*} \\
(0.1439)\end{array}$ & - & $\begin{array}{l}-0.0048 \\
(0.0581)\end{array}$ & - & $\begin{array}{c}0.0326 \\
(0.0238)\end{array}$ & - \\
\hline Private hospital & - & $\begin{array}{l}-0.0010 \\
(0.0036)\end{array}$ & $\begin{array}{l}0.3937^{*} \\
(0.1752)\end{array}$ & - & $\begin{array}{l}-0.0714 \\
(0.0631)\end{array}$ & - & $\begin{array}{c}0.0056 \\
(0.0334)\end{array}$ & - \\
\hline Other private facility & - & $\begin{array}{l}-0.0018 \\
(0.0027)\end{array}$ & $\begin{array}{c}0.2984 \\
(0.2698)\end{array}$ & - & $\begin{array}{l}-0.0729 \\
(0.0716)\end{array}$ & - & $\begin{array}{l}-0.0100 \\
(0.0207)\end{array}$ & - \\
\hline Pharmacy/shop & - & $\begin{array}{l}-0.0035 \\
(0.0031)\end{array}$ & $\begin{array}{l}0.3710^{*} \\
(0.1449)\end{array}$ & - & $\begin{array}{l}-0.1132 \\
(0.0632)\end{array}$ & - & $\begin{array}{c}0.0232 \\
(0.0292)\end{array}$ & - \\
\hline Traditional Healer & - & $\begin{array}{c}0.0068 \\
(0.0069) \\
\end{array}$ & $\begin{array}{c}0.0758 \\
(0.2885) \\
\end{array}$ & - & $\begin{array}{l}-0.0976 \\
(0.0842) \\
\end{array}$ & - & $\begin{array}{l}-0.0313 \\
(0.0278) \\
\end{array}$ & - \\
\hline Observations & & 2108 & 209 & & 786 & & 1202 & \\
\hline
\end{tabular}


TABLE 5

Provider differences by Country (ChLORoQuine, FeVER)

\begin{tabular}{|c|c|c|c|c|c|c|c|c|}
\hline & $\begin{array}{c}\text { Burkina } \\
\text { Faso }\end{array}$ & Benin & Ghana & Guinea & Liberia & Mali & Nigeria & Niger \\
\hline \multicolumn{9}{|l|}{$\begin{array}{l}\text { Chloroquine } \\
\text { only }\end{array}$} \\
\hline \multirow[t]{2}{*}{ Public hospital } & -0.1288 & 0.0401 & $-0.1106^{*}$ & $\begin{array}{c}-0.1424 \\
*\end{array}$ & -0.0635 & -0.1243 & -0.0792 & 0.0676 \\
\hline & $(0.0812)$ & $\begin{array}{c}(0.0444 \\
)\end{array}$ & $(0.0543)$ & $(0.0663)$ & $(0.0579)$ & $(0.1296)$ & $(0.0424)$ & $(0.1220)$ \\
\hline \multirow[t]{2}{*}{$\begin{array}{l}\text { Other public } \\
\text { facility }\end{array}$} & $\begin{array}{c}-0.1149 * * \\
*\end{array}$ & 0.0416 & -0.0982 & -0.0853 & 0.0006 & $-0.1145^{*}$ & -0.0513 & $\begin{array}{c}-0.1583^{*} \\
*\end{array}$ \\
\hline & $(0.0295)$ & $\begin{array}{c}(0.0228 \\
)\end{array}$ & $(0.0588)$ & $(0.0438)$ & $(0.0535)$ & $(0.0494)$ & (0.0399) & $(0.0595)$ \\
\hline \multirow[t]{2}{*}{ Private hospital } & -0.0380 & -0.0494 & $\begin{array}{c}-0.1933 * \\
*\end{array}$ & -0.0985 & -0.0023 & $\begin{array}{c}-0.2507^{*} \\
*\end{array}$ & -0.0288 & 0.0532 \\
\hline & $(0.1787)$ & $\begin{array}{c}(0.0350 \\
)\end{array}$ & $(0.0664)$ & $(0.0766)$ & $(0.0574)$ & $(0.0886)$ & $(0.0487)$ & $(0.1526)$ \\
\hline \multirow[t]{2}{*}{$\begin{array}{l}\text { Other private } \\
\text { facility }\end{array}$} & 0.1932 & -0.0148 & -0.0919 & -0.1811 & 0.0135 & -0.0372 & 0.0422 & -0.0700 \\
\hline & $(0.1240)$ & $\begin{array}{c}(0.0326 \\
)\end{array}$ & $(0.0914)$ & $(0.1107)$ & $(0.0702)$ & (0.1259) & $(0.0434)$ & $(0.0716)$ \\
\hline \multirow[t]{2}{*}{$\begin{array}{l}\text { Pharmacy/sho } \\
\text { p }\end{array}$} & -0.0142 & -0.0204 & -0.0864 & $\begin{array}{c}-0.1194 \\
*\end{array}$ & 0.0142 & -0.1438 & -0.0520 & -0.0282 \\
\hline & $(0.0563)$ & $\begin{array}{c}(0.0327 \\
)\end{array}$ & $(0.0552)$ & $(0.0552)$ & $(0.0624)$ & $(0.0893)$ & $(0.0424)$ & $(0.0797)$ \\
\hline \multirow[t]{2}{*}{$\begin{array}{l}\text { Traditional } \\
\text { Healer }\end{array}$} & 0.0267 & 0.0230 & -0.0766 & -0.1331 & -0.1061 & 0.1318 & $0.2899 *$ & $\begin{array}{c}-0.3943^{*} \\
*\end{array}$ \\
\hline & $(0.1001)$ & $\begin{array}{c}(0.0279 \\
)\end{array}$ & $(0.1027)$ & $(0.1148)$ & $(0.0768)$ & $(0.0690)$ & $(0.1245)$ & (0.1196) \\
\hline Observations & 1361 & 2108 & 663 & 648 & 786 & 628 & 1723 & 676 \\
\hline \multicolumn{9}{|l|}{ Has fever now } \\
\hline \multirow[t]{2}{*}{ Public hospital } & -0.0052 & -0.0378 & $-0.1057^{*}$ & -0.1168 & $\begin{array}{c}-0.2447^{* *} \\
*\end{array}$ & -0.0222 & $-0.0571^{*}$ & 0.0916 \\
\hline & (0.0595) & $\begin{array}{c}(0.0429 \\
)\end{array}$ & $(0.0417)$ & $(0.0686)$ & $(0.0481)$ & $(0.0922)$ & $(0.0261)$ & $(0.0659)$ \\
\hline \multirow[t]{2}{*}{$\begin{array}{l}\text { Other public } \\
\text { facility }\end{array}$} & 0.0144 & -0.0249 & -0.0598 & -0.0290 & $\begin{array}{c}-0.2952^{* *} \\
*\end{array}$ & -0.0336 & -0.0245 & 0.0211 \\
\hline & $(0.0207)$ & $\begin{array}{c}(0.0196 \\
)\end{array}$ & $(0.0439)$ & (0.0319) & $(0.0364)$ & $(0.0290)$ & $(0.0244)$ & $(0.0252)$ \\
\hline \multirow[t]{2}{*}{ Private hospital } & -0.1215 & 0.0202 & -0.1017 & -0.0619 & $\begin{array}{c}-0.2296^{* *} \\
*\end{array}$ & -0.1017 & $-0.0700 *$ & -0.0167 \\
\hline & $(0.1103)$ & $\begin{array}{c}(0.0376 \\
)\end{array}$ & $(0.0662)$ & $(0.1254)$ & $(0.0483)$ & $(0.1026)$ & $(0.0326)$ & $(0.0743)$ \\
\hline \multirow[t]{2}{*}{$\begin{array}{l}\text { Other private } \\
\text { facility }\end{array}$} & -0.1218 & -0.0478 & $\begin{array}{c}-0.2262 * \\
*\end{array}$ & 0.0207 & $\begin{array}{c}-0.2885^{* *} \\
*\end{array}$ & -0.0854 & $\begin{array}{c}-0.1042^{* *} \\
*\end{array}$ & -0.0372 \\
\hline & (0.0639) & $\begin{array}{c}(0.0324 \\
)\end{array}$ & (0.0799) & $(0.0876)$ & $(0.0544)$ & $(0.0730)$ & $(0.0242)$ & $(0.0284)$ \\
\hline \multirow[t]{2}{*}{$\begin{array}{l}\text { Pharmacy/sho } \\
\text { p }\end{array}$} & -0.0254 & -0.0398 & -0.0494 & -0.0519 & $\begin{array}{c}-0.2563^{* *} \\
*\end{array}$ & -0.0285 & -0.0381 & -0.0202 \\
\hline & $(0.0350)$ & $\begin{array}{c}(0.0238 \\
)\end{array}$ & $(0.0417)$ & $(0.0365)$ & $(0.0450)$ & $(0.0601)$ & $(0.0218)$ & $(0.0293)$ \\
\hline \multirow[t]{2}{*}{$\begin{array}{l}\text { Traditional } \\
\text { Healer }\end{array}$} & 0.0192 & 0.0212 & $\begin{array}{c}-0.1883^{*} \\
*\end{array}$ & -0.0228 & $\begin{array}{c}-0.2869 * * \\
*\end{array}$ & -0.0097 & -0.0117 & -0.0401 \\
\hline & $(0.0406)$ & $\begin{array}{c}(0.0220 \\
)\end{array}$ & $(0.0661)$ & $(0.0463)$ & $(0.0488)$ & (0.0299) & $(0.0440)$ & $(0.0558)$ \\
\hline Observations & 2482 & 3661 & 1144 & 1438 & 1372 & 1710 & 4413 & 1849 \\
\hline
\end{tabular}


TABLE 6

ESTIMATION RESULTS FOR GHANA AND NIGERIA FOR 2003 AND 2008

\begin{tabular}{|c|c|c|c|c|}
\hline & \multicolumn{2}{|c|}{ Ghana } & \multicolumn{2}{|c|}{ Nigeria } \\
\hline & 2003 & 2008 & 2003 & 2008 \\
\hline \multicolumn{5}{|l|}{ Antimalarial } \\
\hline \multirow[t]{2}{*}{ Public hospital } & $0.3148^{* * *}$ & $0.4408 * * *$ & $0.4260 * * *$ & $0.2573 * * *$ \\
\hline & $(0.0536)$ & $(0.0656)$ & $(0.0460)$ & $(0.0307)$ \\
\hline \multirow[t]{2}{*}{ Other public facility } & $0.2298 * * *$ & $0.3370 * * *$ & $0.5438 * * *$ & $0.3893 * * *$ \\
\hline & $(0.0599)$ & $(0.0632)$ & $(0.0455)$ & $(0.0257)$ \\
\hline \multirow[t]{2}{*}{ Private hospital } & 0.1119 & $0.5108^{* * *}$ & $0.5288^{* * *}$ & $0.3081^{* * *}$ \\
\hline & $(0.0941)$ & $(0.1051)$ & $(0.0593)$ & $(0.0385)$ \\
\hline \multirow[t]{2}{*}{ Other private facility } & 0.0099 & $0.3446^{*}$ & $0.3694^{* * *}$ & $0.2398 * * *$ \\
\hline & $(0.1751)$ & $(0.1435)$ & $(0.1064)$ & $(0.0238)$ \\
\hline \multirow[t]{2}{*}{ Pharmacy/shop } & $0.1682^{* *}$ & $0.3933^{* * *}$ & $0.3010^{* * *}$ & $0.1434 * * *$ \\
\hline & $(0.0572)$ & $(0.0745)$ & $(0.0318)$ & $(0.0245)$ \\
\hline \multirow[t]{2}{*}{ Traditional healer } & 0.0064 & 0.0224 & -0.0739 & -0.0190 \\
\hline & $(0.1161)$ & $(0.1005)$ & $(0.0456)$ & $(0.0449)$ \\
\hline Observations & 664 & 480 & 1231 & 3182 \\
\hline \multicolumn{5}{|l|}{ Good antimalarial } \\
\hline \multirow[t]{2}{*}{ Public hospital } & - & $0.2957^{*}$ & - & 0.0556 \\
\hline & & $(0.1457)$ & & $(0.0313)$ \\
\hline \multirow[t]{2}{*}{ Other public facility } & - & $0.3561^{*}$ & - & 0.0326 \\
\hline & & $(0.1439)$ & & $(0.0238)$ \\
\hline \multirow[t]{2}{*}{ Private hospital } & - & $0.3937^{*}$ & - & 0.0056 \\
\hline & & $(0.1752)$ & & $(0.0334)$ \\
\hline \multirow[t]{2}{*}{ Other private facility } & - & 0.2984 & - & -0.0100 \\
\hline & & $(0.2698)$ & & $(0.0207)$ \\
\hline \multirow[t]{2}{*}{ Pharmacy/shop } & - & $0.3710^{*}$ & - & 0.0232 \\
\hline & & $(0.1449)$ & & $(0.0292)$ \\
\hline \multirow[t]{2}{*}{ Traditional healer } & - & 0.0758 & - & -0.0313 \\
\hline & & $(0.2885)$ & & $(0.0278)$ \\
\hline Observations & & 209 & & 1202 \\
\hline \multicolumn{5}{|l|}{ Chloroquine only } \\
\hline \multirow[t]{2}{*}{ Public hospital } & -0.0458 & $-0.2404^{*}$ & -0.0782 & -0.0925 \\
\hline & $(0.0706)$ & $(0.0992)$ & $(0.0966)$ & $(0.0492)$ \\
\hline Other public facility & -0.0684 & -0.1970 & -0.1153 & -0.0530 \\
\hline & $(0.0749)$ & $(0.1007)$ & $(0.0970)$ & $(0.0452)$ \\
\hline Private hospital & -0.1178 & $-0.2316^{*}$ & 0.0673 & -0.0772 \\
\hline & $(0.1202)$ & $(0.0903)$ & $(0.1121)$ & $(0.0557)$ \\
\hline Other private facility & -0.0285 & -0.1583 & -0.0590 & 0.0472 \\
\hline & $(0.1654)$ & $(0.1190)$ & $(0.1518)$ & $(0.0463)$ \\
\hline Pharmacy/shop & -0.0071 & -0.1838 & -0.0624 & -0.0466 \\
\hline & $(0.0685)$ & $(0.1002)$ & $(0.0903)$ & $(0.0544)$ \\
\hline Traditional healer & 0.0441 & $-0.2748^{*}$ & 0.3600 & $0.3090^{*}$ \\
\hline & $(0.1432)$ & $(0.1206)$ & $(0.3041)$ & $(0.1430)$ \\
\hline Observations & 454 & 209 & 521 & 1202 \\
\hline Has fever now & & & & \\
\hline Public hospital & $-0.1308^{*}$ & -0.1214 & 0.0703 & $-0.0950 * *$ \\
\hline & $(0.0554)$ & $(0.0677)$ & $(0.0485)$ & $(0.0312)$ \\
\hline Other public facility & -0.0310 & -0.1046 & $0.1007^{*}$ & $-0.0579 *$ \\
\hline & $(0.0631)$ & $(0.0656)$ & $(0.0479)$ & $(0.0281)$ \\
\hline Private hospital & -0.1569 & -0.1091 & -0.0164 & -0.0768 \\
\hline & $(0.0931)$ & $(0.0932)$ & $(0.0584)$ & $(0.0404)$ \\
\hline Other private facility & $-0.2909 *$ & -0.1464 & 0.0158 & $-0.1068^{* * *}$ \\
\hline & $(0.1359)$ & $(0.1145)$ & $(0.0977)$ & $(0.0257)$ \\
\hline Pharmacy/shop & -0.0895 & -0.0721 & 0.0226 & $-0.0575^{*}$ \\
\hline & $(0.0574)$ & $(0.0729)$ & $(0.0368)$ & $(0.0284)$ \\
\hline Traditional healer & -0.1734 & $-0.2645^{* *}$ & 0.0844 & -0.0294 \\
\hline & $(0.1047)$ & $(0.0955)$ & $(0.0700)$ & $(0.0585)$ \\
\hline Observations & 664 & 480 & 1231 & 3182 \\
\hline
\end{tabular}


NOTES: Regression results are based on the full model specification. The reference category is self-medication. ${ }^{*}$ significant at $5 \%, * *$ significant at $1 \%, * * *$ significant at $0.1 \%$. Robust standard errors are in parentheses. We have information available on good antimalarial drugs in year 2008 only.

SOURCE: Authors' calculations based on the DHS 


\section{FIGURES}

\section{FIGURE 1}

MAP SHOWING THE DISTRIBUTION OF MALARIA IN THE WORLD

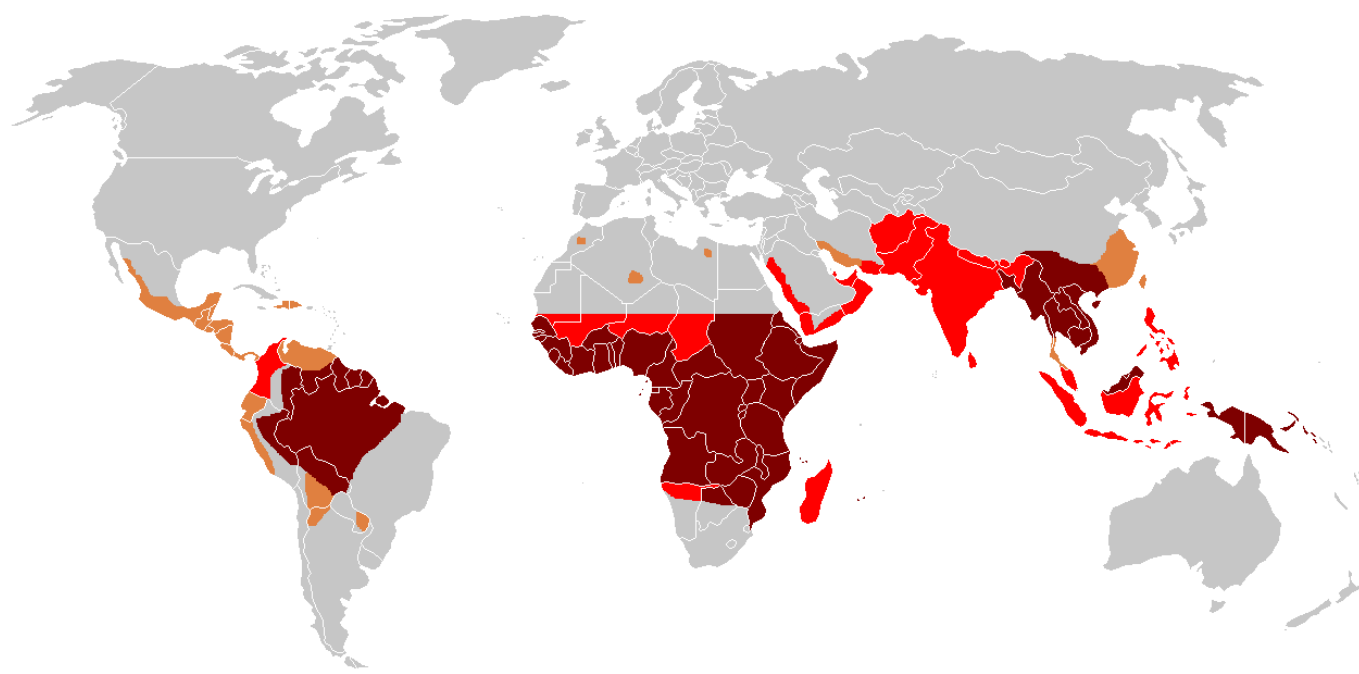

NOTE: Elevated occurrence of chloroquine- or multi-resistant malaria, Occurrence of chloroquineresistant malaria, $\diamond$ No Plasmodium falciparum or chloroquine-resistance, No malaria.

SOURCE: Wikipedia (http://en.wikipedia.org/wiki/Malaria; accessed on 1 April 2013). 


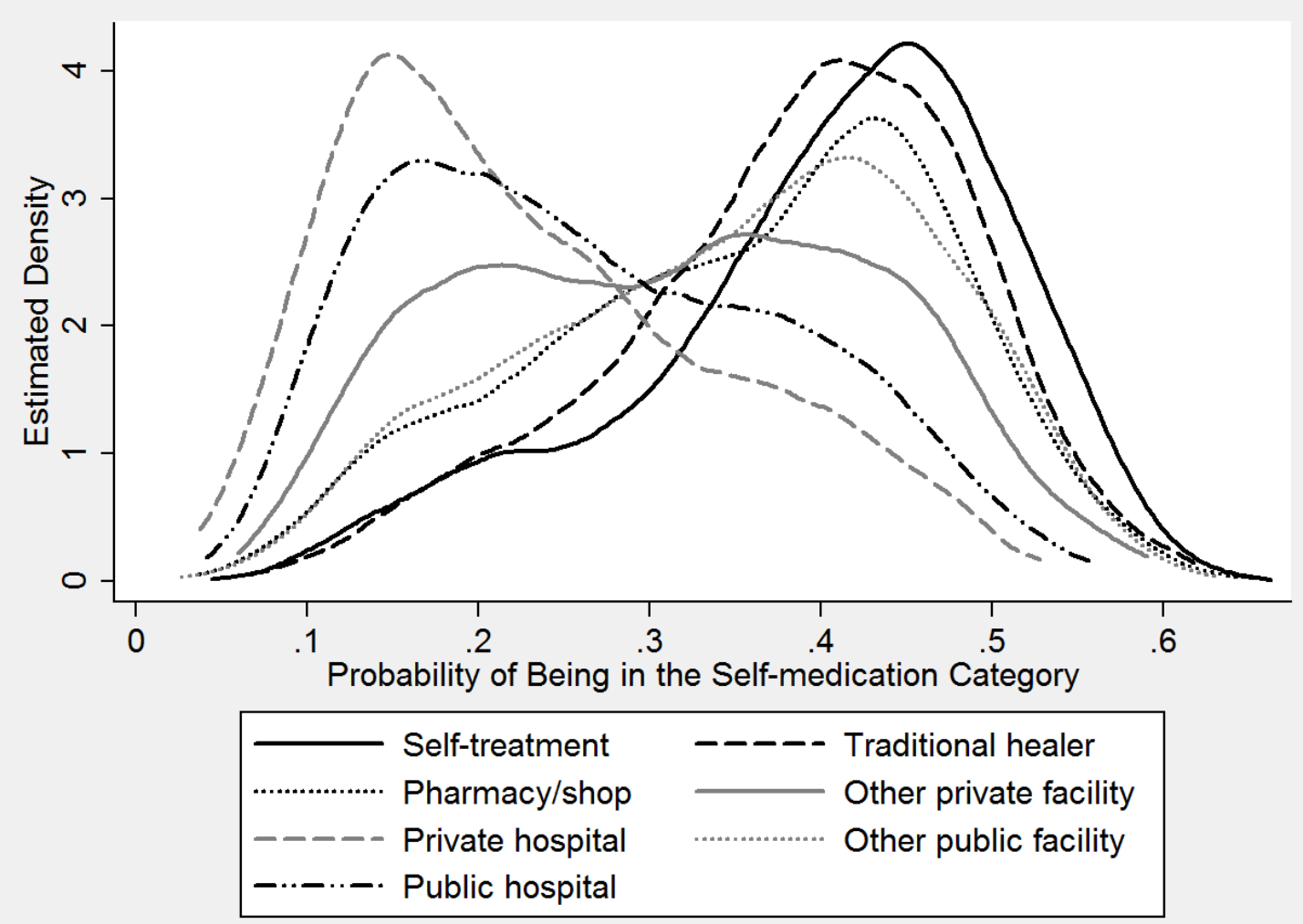

